\title{
Evaldo Marcos Fernandes Rodrigues
}

\section{Novos sensores piezoelétricos com}

elletretos de Tefllon FEP

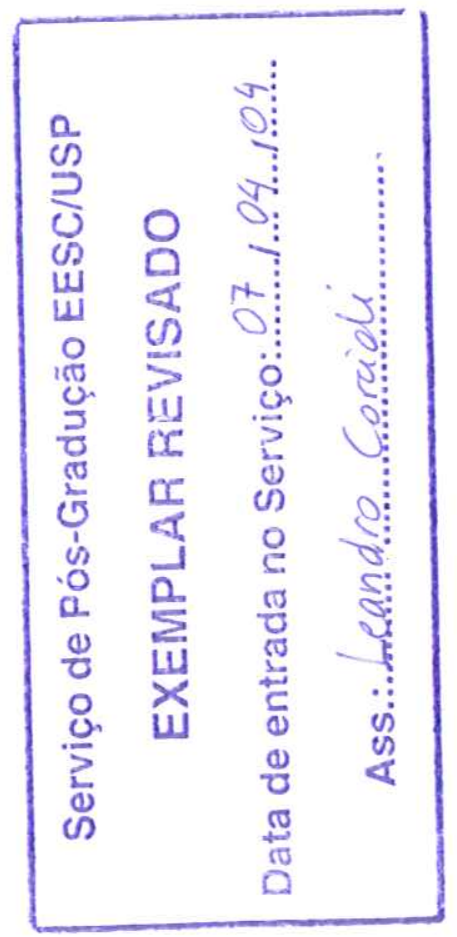

Dissertação apresentada à Escola de Engenharia de São Carlos da Universidade de São Paulo, como parte dos requisitos para a obtenção do título de Mestre em Engenharia Elétrica.

ORIENTADOR: Prof. Dr. Ruy Alberto Corrêa Altafim

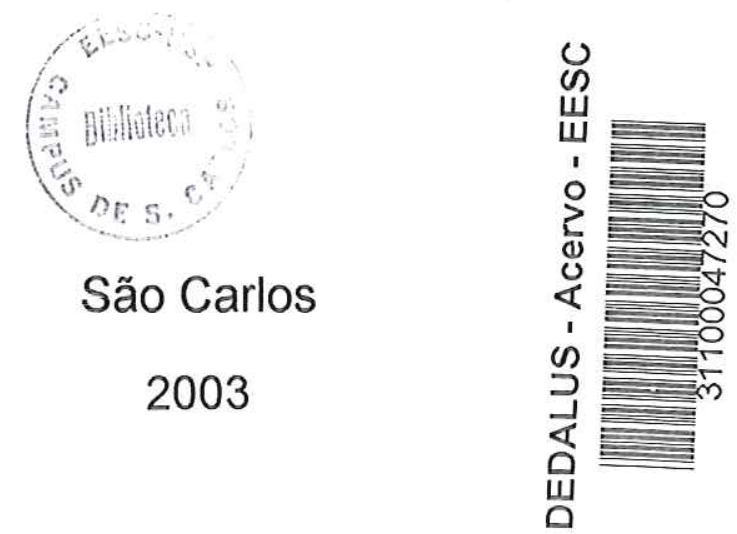


FOLHA DE JULGAMENTO

Candidato: Engenheiro EVALDO MARCOS FERNANDES RODRIGUES

Dissertação defendida e julgada em 06-02-2004 perante a Comissão Julgadora:
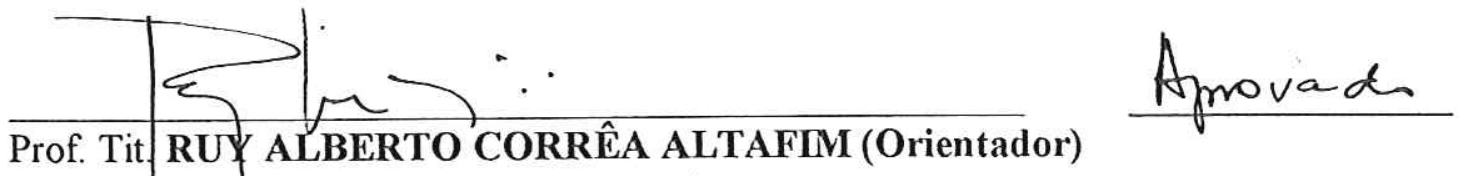

(Escola de Eñoenharia de São Carlos/USP)

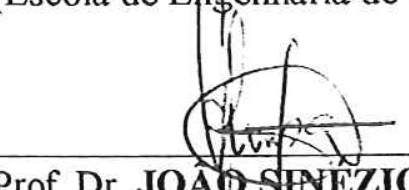

Prof. Dr. JOAPDSINEZIO DE CARVALHO CAMIPOS

(Universidade/Estadual de Campinas/UNICAlyP)

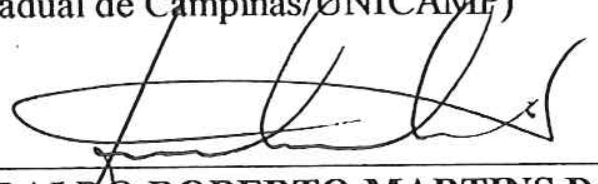

Prof. Assoc. GERALDo ROBERTO MARTINS DA COSTA

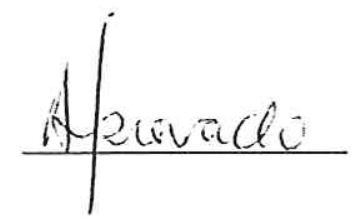

(Escola de Engenharia/de São Carlos/USP)

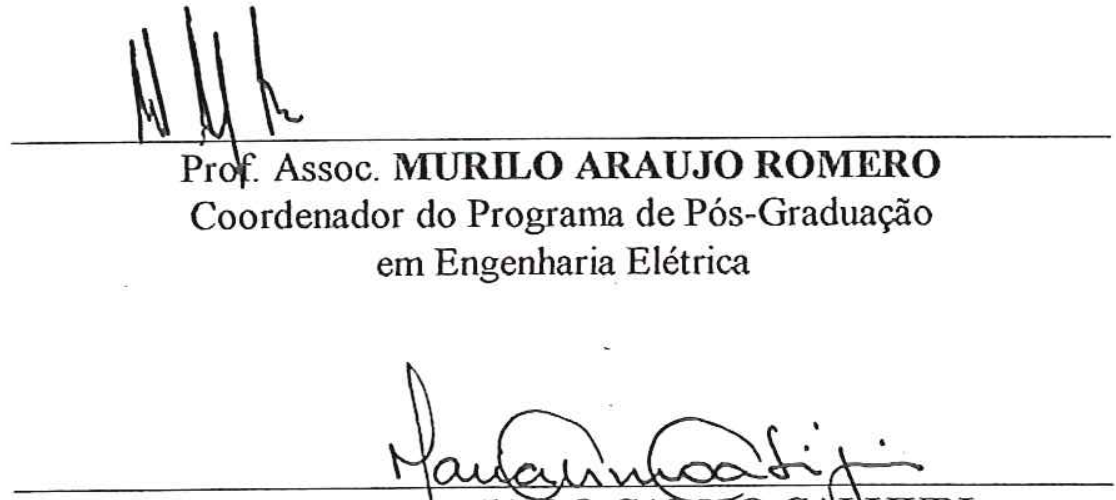

Profa. Assoc. MAARIA DO CARTIO CAUIJURI

Presidente da Comissão de Pós-Graduação 


\section{DEDICATÓRIA}

À minha querida e dedicada esposa Giselda, aos meus queridos filhos Leonardo, Leandro e Renée, pelos preciosos momentos que deixamos de compartilhar em troca do tempo dedicado aos estudos. A todos os meus familiares que contribuíram sobremaneira para a realização deste trabalho. 


\section{AGRADECIMENTOS}

É sempre indelicado não mencionar alguém a quem devemos agradecer por ter participado, de alguma forma, num trabalho nosso; pior, porém, é deixarmos de mencionar aqueles que sempre nos apoiaram e fizeram grandes esforços para ver realizado um sonho nosso.

Por isso, vamos ao mal menor:

Agradeço ao Prof. Dr. Ruy Alberto Corrêa Altafim, pela orientação, pelo incentivo nos momentos de dificuldade e pelo muito que me foi passado em sabedoria através de comentários, discussões e observações sempre pertinentes.

Ao Departamento de Engenharia Elétrica, pelo suporte físico, instrumental e didático que me dispensou durante este período de trabalho.

Aos meus amigos Marcelo Cad, Leandro Lima, Fábio Lima e Leandro Alves Neves, pelos trabalhos extras sempre realizados com amor e dedicação e à Profa. Dra. Cacilda Murakami, pela paciência em ouvir e clareza no falar.

À Companhia Nacional de Energia Elétrica - CNEE, na pessoa de seu diretor presidente, Jorge Queiroz de Moraes Jr., Ph.D., a todos os colaboradores pela atenção nos momentos em que precisei, sem deixar de citar o indispensável e valoroso trabalho de meu irmão Celso Maurício Martins.

E, principalmente a meus pais, Izabel e Nicolau, sempre preocupados e empenhados em apoiar toda e qualquer iniciativa que resulte em nosso engrandecimento pessoal, dentre elas a busca do conhecimento.

Por fim, a todos aqueles que deixei de citar, mas que têm certeza de seu pedacinho de participação no que nos dispusemos a fazer e a DEUS, pela oportunidade de existir. 


\section{SUMÁRIO}

Dedicatória. $i$

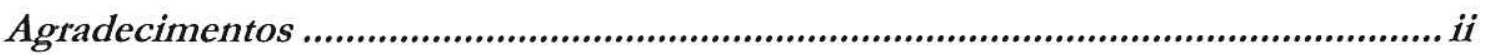

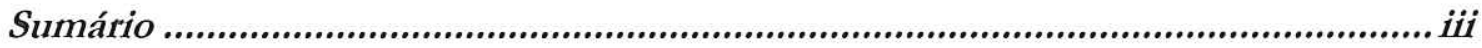

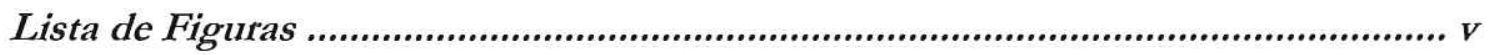

Lista de Fotos............................................................................................. vii

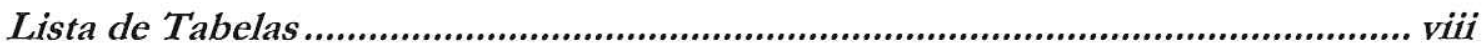

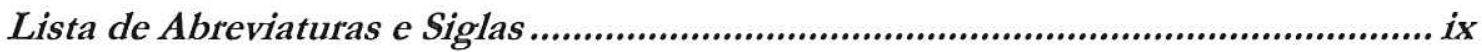

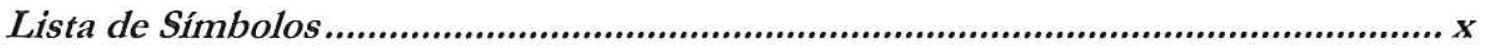

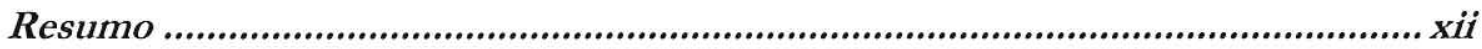

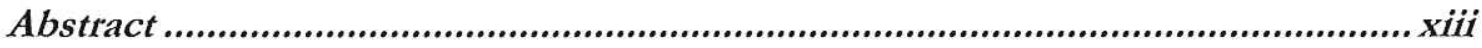

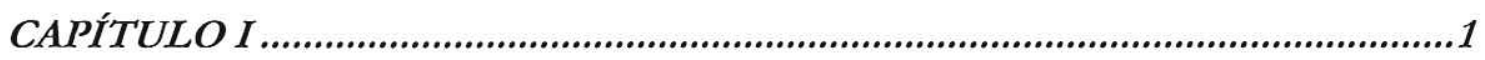

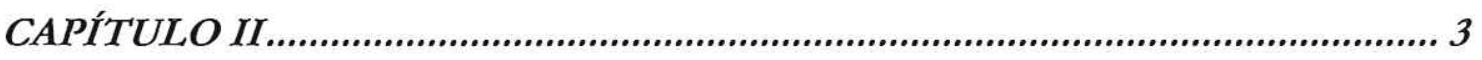

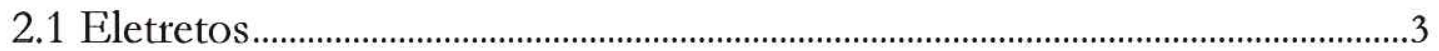

2.2 Processos de Formação de Eletretos.......................................................................

2.2.1 Mecanismo de Termoeletreto.......................................................... 6

2.2.2 Mecanismo de Fotoeletreto ................................................................. 7

2.2.3 Eletretos de Cargas Espaciais Injetadas ............................................. 7

2.2.4 Eletretos por Cargas Depositadas................................................ 10

2.3 Processo de Formação de Eletreto por Tensões Elétricas Impulsivas .. 12

2.4 Comportamento Piezoelétrico dos Polímeros .................................................. 13

2.5 Piezoeletricidade dos Polímeros Porosos ......................................................... 14

2.6 Piezoeletricidade em Polímeros Celulares............................................................ 15

2.7 Polímeros Celulares Carregados por Tensões Impulsivas ............................. 17

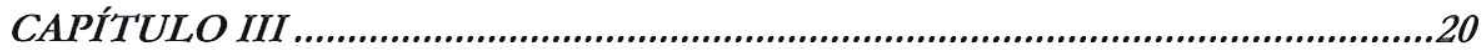

3.1 Idealização do Sensor Piezoelétrico …………………...................................... 20

3.2 Nova Metodologia para Preparação de Amostras ........................................... 21

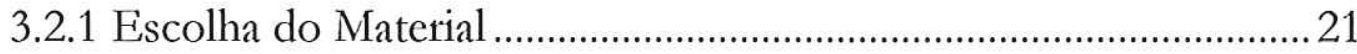

3.2.2 Implantação dos Eletrodos .......................................................... 22

3.2.3 Metodologia para Confecção das Amostras ..................................... 22 


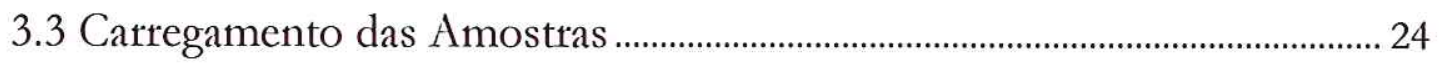

3.4 Medição dos Coeficientes Piezoelétricos ............................................................. 27

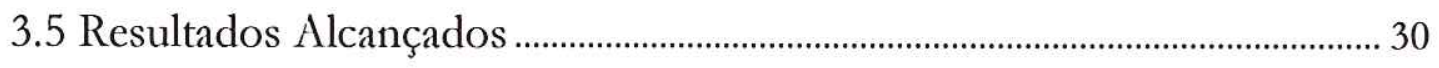

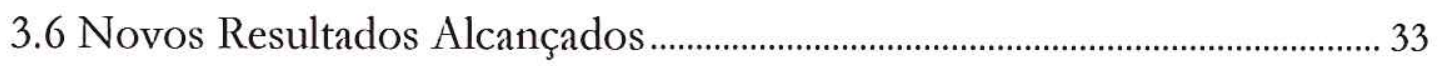

3.7 Repetitividade do Processo...................................................................................... 39

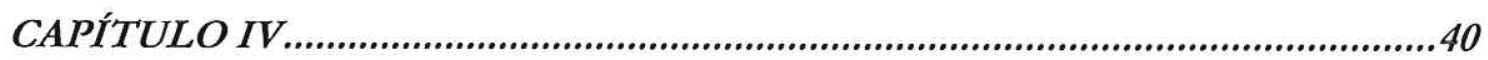

4.1 Considerações Gerais............................................................................................ 40

4.2 Considerações Sobre o Processo de Carregamento ........................................... 40

4.3 Comportamento Piezoelétrico do Novo Sensor ................................................. 45

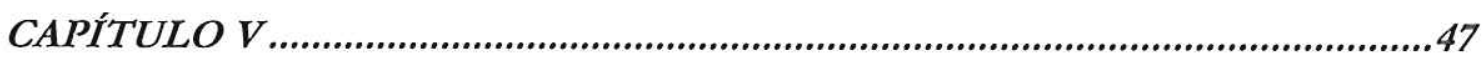

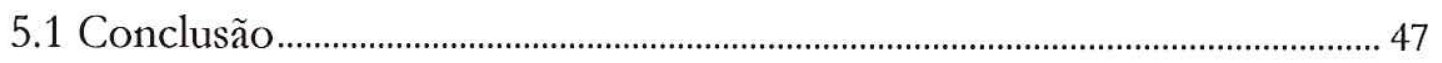

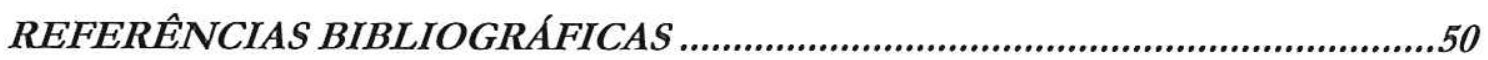




\section{LISTA DE FIGURAS}

Figura 2.1-Diagrama energético de um polímero.

Figura 2.2 - Carregamento de eletreto por injeção de cargas espaciais. (a) Eletrodo intimamente em contato com a amostra; (b) Eletrodo afastado da amostra.

Figura 2.3 - Diagrama esquemático do carregamento de eletretos pelo método de descargas elétricas.

Figura 2.4-Técnica de carregamento de eletretos por descarga corona.

Figura 2.5 - Técnica de carregamento de eletretos por descarga corona com grade (triodo-corona).

Figura 2.6 - Imagem de corte transversal feito em um filme Celular PP de 70 um em duas posições (centro e inferior) feita com um microscópio SEM.

Fìgura 2.7 - Estrutura esquemática do filme poroso, mostrando as cavidades internas em forma de lentes bicôncavas.

Figura 2.8-Estrutura esquemática do filme poroso, mostrando as cavidades internas em forma de lentes bicôncavas com os carregamentos.

Figura 2.9 - (a) Mostra o circuito elétrico com o gerador de impulso e a amostra e (b) Mostra as características da curva de tensão de impulso.

Figura 3.1 - Mostra a forma construtiva das amostras e a disposição das lâminas de Teflon FEP e dos eletrodos de alumínio. 
Figura 3.2 - Circuito de ensaio usado no carregamento das amostras. Sendo $R 1=72$ $\Omega, R 2=44 \Omega, C 1=1,35 m F$ e $C 2=11 n F$.

Figura 3.3 - Arranjo para a medição do coeficiente piezoelétrico.

Figura 3.4 - Medição em osciloscópio da tensão gerada por uma amostra quando submetida a uma descompressão de $20 \mathrm{~N}$.

Figura 3.5 - Medição em osciloscópio feita na compressão da amostra quando submetida a uma carga de $20 \mathrm{~N}$ na direção vertical.

Figura 3.6 - Coeficiente piezoelétrico em função da tensão de impulso de carregamento.

Figura 3.7 - Curvas Carga [pC] x Massa aplicada na descompressão [g] para cada tensão de carregamento [kV]

Figura 3.8 - Curva Carga [pC] x Massa aplicada na descompressão [g] para a Amostra G7 - Carregada com 5,88 kV

Figura 3.9 - Coeficiente Piezoelétrico [pC/N] x Peso aplicado na descompressão [N] para a amostra $G 7$ - carregada com $5,88 \mathrm{kV}$

Figura 3.10 - Repetitividade dos valores de carga elétrica encontrados em uma série de amostras carregadas com uma mesma tensãoImpulsiva $-5,88 \mathrm{kV}$

Figura 4.1 - Diagrama esquemático para carregamento de eletretos por tensões impulsivas.

Figura 4.2 - Interstício existente entre as folhas de Teflon FEP quando separadas por goticulas de verniz.

Figura 4.3 - Arranjo para um eletreto formado por tensões impulsivas.

Figura 4.4 - Alteração das espessuras das cavidades de ar alteram o efeito piezoelétrico. 


\section{LISTA DE FOTOS}

Foto 3.1 - Amostra de Teflon FEP com duas lâminas em bastidor de alumínio e eletrodos unidos por verniz, preparada para o carregamento com tensão impulsiva.

Foto 3.2 - Equipamento e circuito de carregamento por tensões impulsivas.

Foto 3.3 - Equipamento e circuito de medida. 


\section{LISTA DE TABELAS}

Tabela 1 - Medições das tensões nas amostras - descompressão.

Tabela 2 - Cálculo dos coeficientes de piezoeletricidade $d_{33}$.

Tabela 3 - Medições das cargas nas amostras - descompressão.

Tabela 4 - Médias dos valores encontrados nas medições das cargas nas amostras descompressão.

Tabela 5-Medições das cargas na amostra selecionada (G7) - descompressão.

Tabela 6 - Cargas elétricas armazenadas nas amostras da série G com peso de $10 \mathrm{~N}$. 


\section{LISTA DE ABREVIATURAS E SIGLAS}

\begin{tabular}{|c|c|}
\hline$P P$ & - Polipropileno \\
\hline PTFE & - Politetrafluoretileno \\
\hline$P V D F$ & - Polifluoreto de vinilideno \\
\hline$F E P$ & - Polifluoretileno \\
\hline$C d S$ & - Sulfeto de Cádmio \\
\hline PET & -Polietileno tereftalato \\
\hline $\mathrm{CO}_{3}^{-}$ & - íon Carbonato \\
\hline$P M G$ & -Polimetil-L-glutamato \\
\hline$A F$ & - Fluorpolímeros Amorfos \\
\hline$H F P$ & - Hexafluorpropileno \\
\hline $\mathrm{SiO}_{2}$ & - Dióxido de Silício \\
\hline
\end{tabular}




\section{LISTA DE SÍMBOLOS}

\begin{tabular}{|c|c|}
\hline$T e$ & - armadilhas elétrons \\
\hline$T h$ & - armadilhas buracos \\
\hline$t_{e r}$ & - tempo \\
\hline$L$ & - comprimento $(\mu m)$ \\
\hline$V$ & -tensão (Volt) \\
\hline$\mu$ & - mobilidade do portador \\
\hline$\sigma$ & - densidade superficial de cargas \\
\hline$e V$ & - elétron volt \\
\hline$d_{33}$ & - coeficiente piezoelétrico \\
\hline$C$ & - capacitância \\
\hline$P$ & - carga mecânica \\
\hline$j_{c}$ & - densidade de corrente \\
\hline$V_{s}$ & - potencial de superficie em circuito aberto \\
\hline$V g$ & - potencial no interstício \\
\hline$\varepsilon$ & - permitividade relativa do dielétrico \\
\hline$\varepsilon_{0}$ & - permitividade relativa do vácuo \\
\hline
\end{tabular}


$d$

- espessura do interstício de ar

$\alpha$

- coeficiente de ionização (primeiro coeficiente de Townsend)

$\gamma$

- segundo coeficiente de Townsend 


\section{RESUMO}

RODRIGUES, E. M. F. (2003). Novos sensores piezoelétricos com eletretos de Teflon FEP. Dissertação (Mestrado) - Escola de Engenharia de São Carlos, Universidade de São Paulo, São Carlos, 2003.

Esta dissertação aborda fundamentalmente a formação de eletretos de Teflon FEP em múltiplas camadas com carregamento por descargas impulsivas de alta tensão. Devido a suas excelentes qualidades piezoelétricas, eles serão destinados a sensores de pressão em múltiplas aplicações.

Este tipo de eletreto foi escolhido por se utilizar materiais com grande disponibilidade no mercado e de custo bastante reduzido. O processo de carregamento por altas tensões impulsivas também foi escolhido devido à sua simplicidade, segurança e tempo reduzido.

Para se obter maior valor de constantes piezoelétricas foi utilizado o processo de formação de eletretos por multicamadas, e a metodologia empregada utiliza verniz tanto na união das folhas de Teflon FEP quanto na junção dos eletrodos de alumínio. Dessa forma, microbolhas de ar são criadas entre os materiais, que carregadas eletricamente, formando o eletreto. Com tal artifício, é possível obter coeficientes piezoelétricos $\mathrm{d}_{33}$ elevados sem o uso de materiais de alta tecnologia ou de restrita tecnologia.

O método de obtenção do eletreto apresenta um custo extremamente reduzido - pelo emprego de materiais simples e de fácil obtenção - e a diversidade de possibilidades de aplicações, o que torna o método bastante atraente, podendo, ainda, tornar o País independente de tecnologia importada.

Palavras-chave: piezoeletricidade; eletretos. 


\section{ABSTRACT}

RODRIGUES, E. M. F. (2003). New piezoelectric sensor with electrets FEP Teflon. M.Sc. Dissertation - Escola de Engenharia de São Carlos, Universidade de São Paulo, São Carlos, 2003.

This dissertation approaches fundamentally the formation of electrets of Teflon FEP in multiple layers by impulsive discharges. Due to their excellent piezoelectric qualities, they will be destined to sensors of pressure in multiple applications.

This electret type was chosen due to its easiness of obtaining, by using low-cost common materials easily found in the market. The process of loading by high impulsive tensions was chosen due to its simplicity, safety and reduced necessary time.

To reach higher values of piezoelectrics constant the process of electrets formation in multilayers was used, and the methodology employed varnish in the union of both FEP Teflon films and aluminum electrodes. In this way, micro bulbs of air is created among the materials, which were later loaded electrically, forming the electret. With such artifice, it is possible to obtain high piezoelectrics $d_{33}$ coefficients without using materials of high or restricted technology.

The simplicity of the method of electret obtaining, the extremely reduced cost - by the use of simple and easy - of - obtaining materials - and the diversity of application possibilities, make the method quite attractive. By using such method, the Country may even become independent of imported technology.

Keywords-: piezoelectricity; electrets. 


\section{CAPÍTULO I}

INTRODUÇÃO

A propriedade piezoelétrica de muitos materiais sempre interessou à área de engenharia elétrica, em função de suas múltiplas aplicações como transdutores eletromecânicos de pressão, ou sua propriedade inversa voltada à produção de vibrações mecânicas.

Até meados da década de sessenta do século passado, os cristais piezoelétricos reinavam absolutos, em agulhas de toca-discos, em microtransdutores de pressão ou em transdutores eletroacústicos. Surge aí a proposta, feita por pesquisadores japoneses, de usar filmes políméricos em aplicações piezoelétricas, tendo como grande vantagem o fato de poderem ser usados em grandes áreas e com custos reduzidos. Desde então, muitos polímeros foram se desenvolvendo, a exemplo do politetrafluoretileno (PTFE) e do polifluoreto de vinilideno (PVDF), que são ainda os melhores polímeros para serem utilizados como eletretos de cargas espaciais e dipolo, respectivamente. Entretanto, recentemente uma nova área de pesquisa está surgindo com polímeros celulares e porosos para a confecção de eletretos com altíssimos coeficientes piezoelétricos, superiores inclusive aos melhores polímeros ferroelétricos.

Esta pesquisa, que emprega sanduíches de Teflon FEP com características específicas e a formação de eletretos por tensões impulsivas, apresenta um novo detetor piezoelétrico. Um outro importante ponto desta dissertação a ser ressaltado é apresentar uma nova tecnologia que pode eliminar a dependência tecnológica com relação aos polímeros porosos e celulares, e que possibilita o aumento do controle em todo o processo de carregamento dos eletretos, hoje um dos principais problemas desses polímeros. 
Esta dissertação está organizada em cinco capítulos seguindo basicamente a orientação descrita nos parágrafos subseqüentes.

No capítulo II, é realizada uma extensa pesquisa bibliográfica, procurando dar suporte teórico ao trabalho desde o que se entende por eletreto, o seu processo de formação até às suas características piezoelétricas.

O capítulo III é dedicado à parte experimental, onde se pôde mostrar como os diferentes sensores podem ser fabricados, seus testes e resultados de resposta em diferentes freqüências.

No capítulo IV, é dada uma proposta para a explicação teórica do sensor.

Finalmente, no capítulo V, foram apresentadas as conclusões e propostas de trabalhos futuros. 


\section{CAPÍTULO II \\ REFERÊNCIAS BIBLIOGRÁFICAS \\ Neste capitulo será feita uma revisão bibliográfica \\ procurando trajar o caminho que condurin ao \\ desenvolvimento deste trabalho.}

\subsection{ELETRETOS}

Em 1839 com a publicação dos estudos clássicos de Michael Faraday, inicia-se a história dos eletretos [1]. Procurando intuitivamente explicar o fenômeno em que um capacitor carregado, um longo período depois de ter suas placas momentaneamente curto-circuitadas, apresentava ainda um carregamento elétrico inferior ao inicial, Faraday propôs que, durante o carregamento, cargas estariam migrando do eletrodo para o dielétrico. Essa explicação ficou por um tempo esquecida.

O termo eletreto só foi estabelecido por Oliver Heaviside em 1895, em analogia aos magnetos, para explicar ou designar dielétricos polares que poderiam apresentar um campo elétrico residual. Esse fenômeno e outros envolvidos na formação dos eletretos, na verdade, só foram precisamente compreendidos em meados do século passado por Bernhard Gross [2, 3, 4].

Eletretos são, em suma, dielétricos que apresentam um campo elétrico residual análogo aos ímãs permanentes. Basicamente, dois são os fenômenos que podem explicar um campo elétrico residual em um dielétrico: o da polarização dielétrica e o das cargas elétricas aprisionadas.

Os primeiros eletretos polares foram fabricados com resinas de cera de carnaúba em 1919 pelo físico japonês Mototaro Eguchi [5], baseados na teoria da 
polarização dielétrica estabelecida por Peter Debye. Aquecendo a resina na presença de um campo elétrico e, depois, esfriando-a, ele obteve um forte campo elétrico residual, em razão de uma polarização permanente dela. A esse fenômeno, sem ter feito menção a Heviside, ele também atribuiu o nome de eletreto. Hoje, este nome é aceito universalmente.

De acordo com a definição de eletreto dada por Gerhard-Multhaupt [6], tem-se:

Piezeletricidade é um fenômeno estritamente linear que relaciona qualquer deslocamento mecânico e tensão elétrica, e qualquer tensão elétrica e deslocamento mecânico como causa e efeito, respectivamente.

A década de 90 viu surgir novos materiais dielétricos porosos e celulares que apresentam coeficientes piezoelétricos altíssimos quando carregados eletricamente, formando "Eletretos-piezoelétricos". Esses novos eletretos tornam viáveis o uso de folhas extremamente finas como sensores de pressão, em inúmeras aplicações. Devido à sua grande importância tecnológica e sua originalidade, esses materiais ainda são mantidos fora do mercado, existindo praticamente apenas no interior de grandes laboratórios de multinacionais. Desta forma, qualquer tipo de estudo com esses materiais torna-se difícil ou, muitas vezes, impossível.

Procurando suprir esta deficiência, neste trabalho, foi desenvolvido um novo sensor piezoelétrico com processo tecnológico totalmente nacional e que compete com aqueles confeccionados com polímeros porosos e celulares. Também foram desenvolvidas as metodologias para a sua construção e para a medição de seu coeficiente piezoelétrico estático. Foi também delineada uma explicação teórica sobre todo o sensor baseada no princípio de carregamento de eletretos por tensões impulsivas. 


\subsection{PROCESSOS DE FORMAÇÃO DE ELETRETOS}

A partir do processo de formação desenvolvido por Eguchi, a moderna ciência dos eletretos desenvolveu-se rapidamente nas décadas recentes [7, 8]. Eletretos já podem ser conseguidos com materiais amorfos, policristalinos ou substâncias parcialmente cristalinas, nos quais, os níveis energéticos locais são afetados por seu arranjo molecular, fazendo com que cada átomo, ou grupo atômico, tenha seu próprio nível energético. Em conseqüência, as bandas energéticas, como as que são mostradas na figura 2.1, apresentam inúmeras deformações, e que são denominadas armadilhas, que podem capturar elétrons ou buracos.

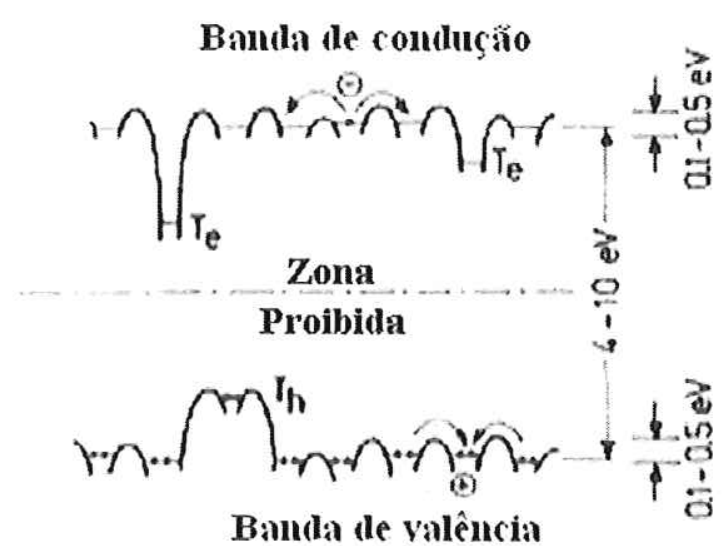

a

Banda de valência

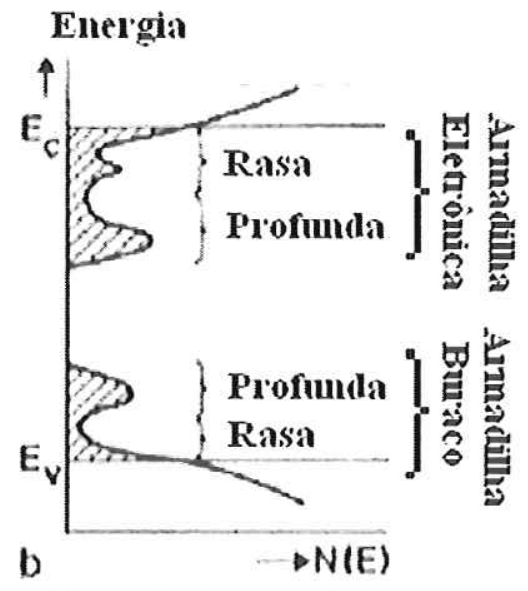

Densidale de estado

Figura 2.1 - Diagrama energético de um polímero. $T_{e}$ representa as armadilhas Elétrons e $T_{h}$ as armadilhas buracos.

A armadilha denomina-se profunda ou rasa, de acordo com o nível da banda de condução, e é medida em elétron-volt (eV). Dois tipos básicos de armadilhas podem ser encontrados nos polímeros: as de volume e as de superfície. As armadilhas de volume são provenientes, principalmente, de impurezas, de irregularidades das cadeias moleculares e das imperfeições nos cristalinos, enquanto as armadilhas de superfície são devidas às impurezas químicas, aos defeitos superficiais causados por produtos 
oxidantes, pela quebra de cadeias ou por moléculas absorvidas. Para o Teflon FEP, nos experimentos com corrente termoestimulada $[9,10]$ a predominância é de armadilhas superficiais. As armadilhas de elétrons apresentam energia de ativação de 1,2 eV e ocorrem entre 0 e $0,5 \mu \mathrm{m}$ da superfície da amostra. Nos materiais carregados negativamente, os elétrons, na sua maioria, são capturados pelas armadilhas profundas próximas da superfície do material e, ali, podem permanecer por longos períodos [11].

Esta pequena introdução teórica fornece elementos conceituais que facilitam o entendimento dos principais mecanismos de formação de eletretos com excesso de cargas descritos nos itens seguintes.

\subsubsection{MECANISMO DE TERMOELETRETO}

Em materiais eletricamente neutros e que também apresentem cargas espaciais em seu interior, ocorre uma distribuição aleatória dessas cargas que ficam aprisionadas em armadilhas, não apresentando externamente qualquer momento de dipolo. No entanto, quando elas são separadas e se fixam em novas posições, geram um efeito correspondente a um dipolo macroscópico, ou seja, tem-se a formação de um eletreto.

Na separação dessas cargas, pode-se empregar o mesmo procedimento térmico dos eletretos dipolares discutido por Sessler [11]. O tempo de aplicação do campo elétrico externo deve ser comparável ao tempo de trânsito dos portadores na temperatura de formação, e é expresso por:

$$
t_{c r}=\frac{L^{2}}{\mu V}
$$

sendo L, o comprimento transversal da amostra; $\mu$ a mobilidade do portador mais rápido; e $\mathrm{V}$ a tensão aplicada. 
Esses tempos são muito variáveis, podendo oscilar de alguns milissegundos até centenas de anos. Também, pode-se observar que são fortemente dependentes da temperatura em que se encontra a amostra no instante da formação do eletreto.

\subsubsection{MECANISMO DE FOTOELETRETO}

Ao serem irradiados com luz ultravioleta ou luz visível, os materiais fotocondutores, na presença de um campo elétrico e cobertos com um ou dois eletrodos transparentes, conservam, depois de removido o campo elétrico e de terminada a irradiação, uma forte polarização, criando-se um fotoeletreto. É necessário, no entanto, que a luz irradiada possua energia suficiente para remover os elétrons de sua banda de valência criando pares elétrons-buracos. Dessa forma, esses portadores livres podem mover-se, sob a ação do campo elétrico, para uma das extremidades do material.

Os fotoeletretos mais recentes têm sido obtidos com o uso de filmes finos de sulfeto de cádmio (CdS) e com semicondutores amorfos [11, 12].

\subsubsection{ELETRETOS DE CARGAS ESPACIAIS INJETADAS}

Ao ser aplicado aos eletrodos de uma configuração mostrada na figura 2.2 um campo elétrico suficientemente forte (de aproximadamente $10^{5} \mathrm{~V} / \mathrm{m}$ ), pode ocorrer uma migração de cargas elétricas do eletrodo para o dielétrico. Estando o eletrodo intimamente em contato com o dielétrico, haverá transferência direta de cargas: caso isso não ocorra, a transferência se dará através da descarga elétrica no ar. Ocorrida a transferência de cargas e, retirado o campo elétrico, ficará um campo elétrico remanescente com características elétricas estáveis, ou seja, ocorreu a criação de um eletreto. As cargas elétricas de mesmo sinal que o eletrodo adjacente indicam que a formação do eletreto ocorreu devido às homocargas. 


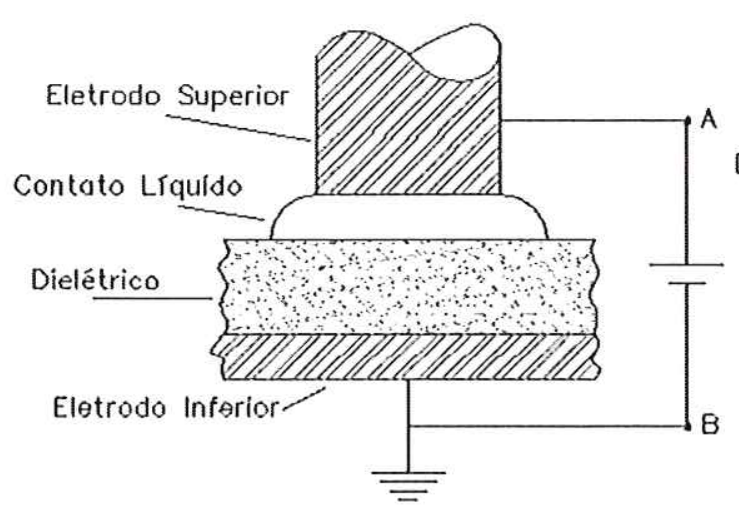

(a)

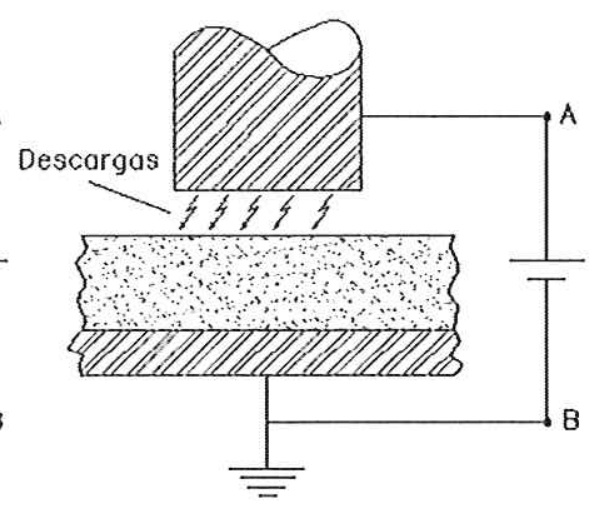

(b)

Figura 2.2-Carregamento de eletreto por injeção de cargas espaciais. (a) Eletrodo intimamente em contato com a amostra; (b) Eletrodo afastado da amostra.

Para melhor eficiência no carregamento por transferência de cargas, é feito o contato entre o eletrodo e o dielétrico através de uma fina camada líquida de água ou de álcool etílico $[13,14,15]$. Para o processo de carregamento por descarga, muitos processos têm sido estudados em busca da melhor eficiência encontrando-se bons resultados $[16,17]$. Usando-se este método, densidades de carga maiores que $10^{-6} \mathrm{C} / \mathrm{cm}^{2}$ são depositadas em folhas de polietileno tereftalato - PET, empregado por Sessler e West [15], que usaram uma configuração semelhante a um "sanduíche" contendo o dielétrico e uma fina camada de material de resistividade menor (lâmina de vidro de 0,1 a $0,3 \mathrm{~cm}$ de espessura com condutividade aproximada de $10^{-12} \mathrm{~S} / \mathrm{cm}$ ). A figura 2.3 ilustra esquematicamente a configuração mencionada.

Cabe ainda uma importante observação sobre a técnica de carregamento descrita; trata-se da necessidade da imediata remoção do eletrodo superior de forma a evitar que a amostra se descarregue por efeito de ruptura reversa de Paschen, efeito este posteriormente descrito. 


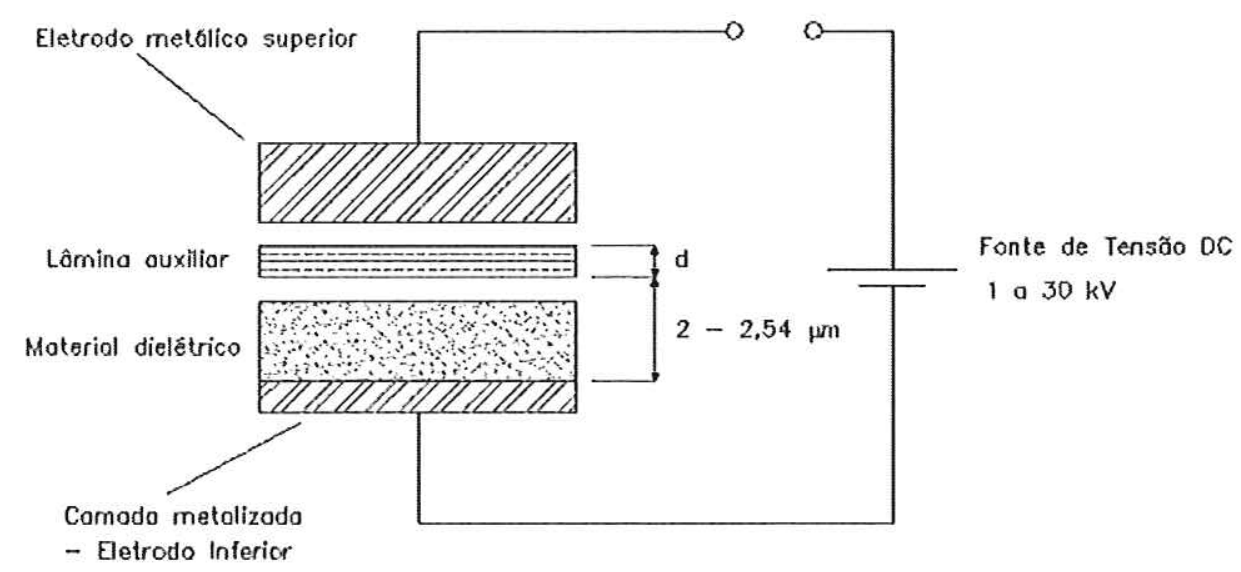

Figura 2.3 - Diagrama esquemático do carregamento de eletretos pelo método de descargas elétricas.

Posteriormente, a lâmina de vidro foi substituída por uma folha isolante do mesmo material dielétrico de que é formado o eletreto, como propuseram Medycki e Hilczer [18], com sensível redução no tempo de carregamento.

Por esse método, a deposição de cargas sobre o dielétrico é devida a espécies iônicas tal como ocorre no carregamento corona, descrita no item seguinte, e a carga armazenada no dielétrico é limitada por rupturas elétricas internas e externas ao material.

A ocorrência da ruptura interna de um dielétrico relaciona-se intimamente à rigidez dielétrica do material. No caso dos polímeros, como a rigidez dielétrica é elevada - da ordem de MV/cm (para o Teflon FEP é da ordem de 2,2 x $10^{6} \mathrm{~V} / \mathrm{cm}$ ) -, a ruptura interna dificilmente ocorre. No entanto, o mesmo não acontece com a ruptura externa, também conhecida como ruptura reversa de Paschen, que acontece muito mais freqüentemente por ser função da geometria dos eletrodos, da composição do gás e da pressão. 


\subsubsection{ELETRETOS POR CARGAS DEPOSITADAS}

Muito similar aos eletretos anteriormente descritos, este tipo de eletreto recebe a injeção de cargas por meio de bombardeio do material dielétrico com uma descarga corona no ar ou através de um feixe eletrônico no vácuo. Quando se usa o método da deposição por efeito corona, os íons são gerados ao ser aplicada alta tensão em uma ponta colocada a certa distância de uma das faces da lâmina do dielétrico, da forma como ilustra a figura 2.4 .

Se a ponta apresenta polaridade negativa, como geralmente ocorre no carregamento do Teflon FEP, os portadores negativos fluem para o dielétrico. No ar, na pressão atmosférica, os íons $\mathrm{CO}_{3}{ }^{-}$são os principais portadores. Devido à sua pequena energia térmica, esses íons são depositados na superfície do material, e supõe-se que suas cargas são transferidas para as 'armadilhas' superficiais do material. A penetração de cargas no material depende da polaridade, de sua densidade e das características do próprio material isolante. No Teflon, por exemplo, as cargas negativas penetram muito pouco para densidade de cargas em torno de $10^{-8} \mathrm{C} / \mathrm{cm}^{2}$, enquanto as cargas positivas penetram substancialmente no material. Neste processo de carregamento, o potencial de superfície remanente do eletreto pode ser controlado pela tensão da grade existente entre a ponta e o dielétrico, sendo viável obter amostras dielétricas com potenciais de superfície de algumas centenas de volts [19, 20]. 


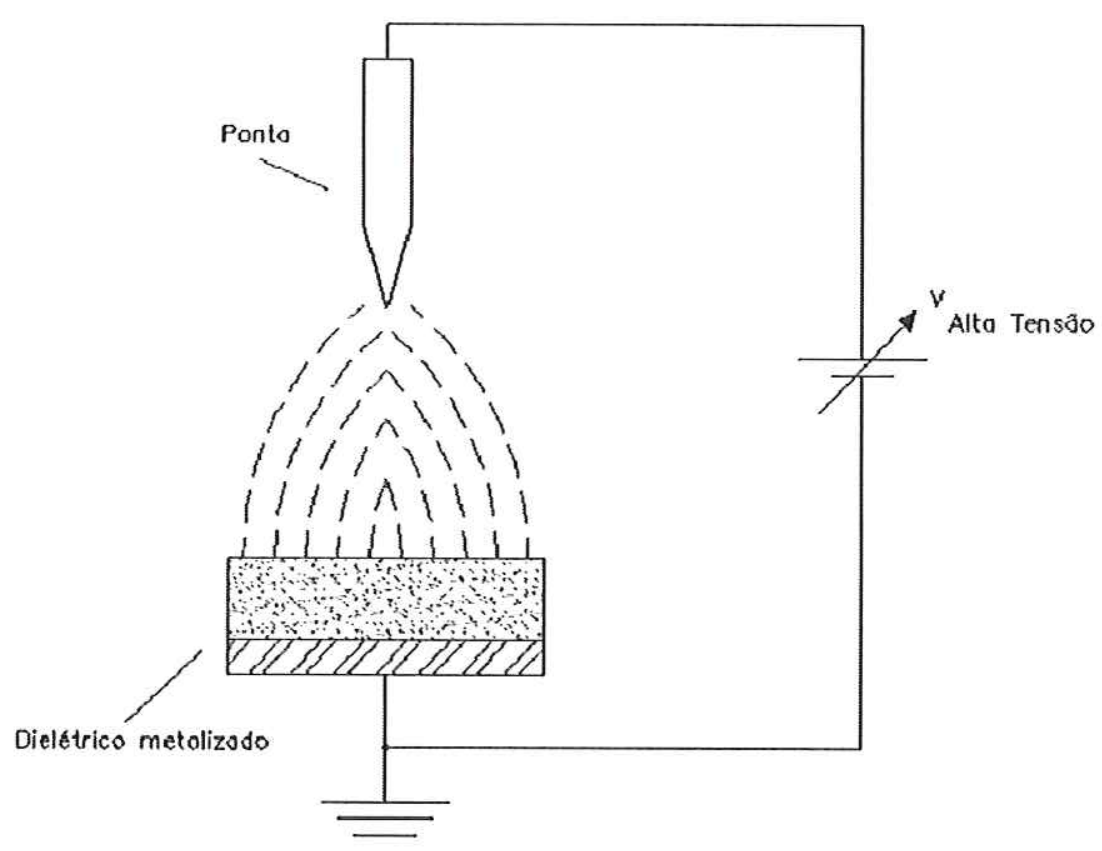

Figura 2.4 - Técnica de carregamento de eletretos por descarga corona.

Este método apresenta alguns inconvenientes, sendo o maior deles a não uniformidade da distribuição de cargas [21, 22]. Por isso, um dispositivo auxiliar foi arranjado de forma a haver melhor homogeneidade na distribuição das cargas injetadas na amostra.

A figura 2.5 apresenta as alterações feitas na configuração primitiva, com a implementação de uma grade metálica também submetida a tensão controlada. Desta forma, a distribuição de carga na placa a ser carregada passa a ser uniforme e facilmente controlada [23]. 


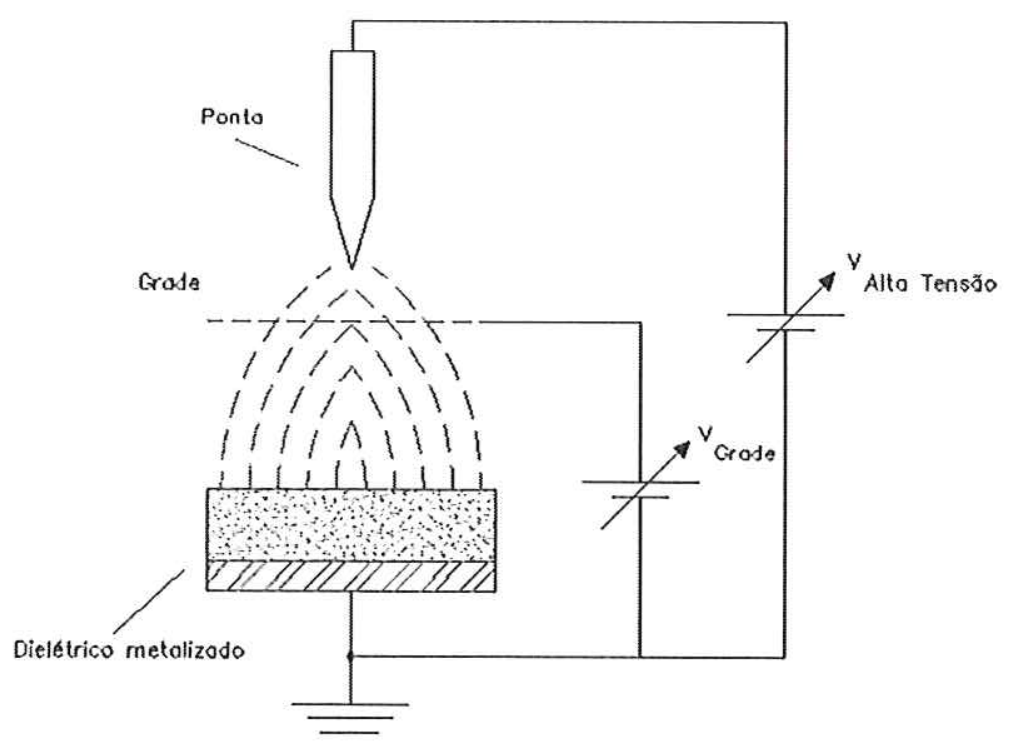

Figura 2.5 - Técnica de carregamento de eletretos por descarga corona com grade (triodocorona). A grade pode ou não apresentar controle de tensão.

Para o carregamento corona também é necessário tempo bastante prolongado e temperaturas elevadas, motivo pelo qual outros métodos foram apresentados com algumas vantagens.

\subsection{PROCESSO DE FORMAÇÃO DE ELETRETO POR TENSÕES ELÉTRICAS IMPULSIVAS}

O processo de formação de eletretos por tensões impulsivas foi desenvolvido por Altafim et al. [9] em 1991 e explicado fisicamente em 1998 [24]. Nesse método, uma tensão impulsiva singela com formato dado pela equação (2.2) é aplicada sobre dois eletrodos separados por um dielétrico, no caso Teflon FEP. As cargas elétricas transferidas do eletrodo superior para o dielétrico por descargas elétricas armazenam-se em armadilhas energéticas superficiais profundas, criando um eletreto do tipo cargas espaciais. Esse método como uma das principais vantagens seu curtíssimo tempo de carregamento, da ordem de microssegundos e sua extrema simplicidade. 


$$
v(t)=v_{0}\left(e^{-\alpha_{1} \cdot t}-e^{-\alpha_{2} t}\right)
$$

onde $\mathrm{v}_{0}$ é a tensão de pico, e $\alpha_{1}$ e $\alpha_{2}$ são constantes de tempo, conhecidas como constantes de Townsend, que serão descritas adiante.

\subsection{COMPORTAMENTO PIEZOELÉTRICO DOS POLÍMEROS}

O efeito piezoelétrico foi descoberto em 1880 pelos irmãos Jacques e Pierre Curie e, desde então, intensos estudos foram feitos para detectar os efeitos em outros materiais. As primeiras investigações das propriedades ocorreram em 1924 com Brain [25], estudando a celulose. Contudo, as pesquisas em larga escala dessas propriedades só passaram a acontecer no final dos anos 1950 .

Pesquisadores japoneses, em 1968, sugeriram pela primeira vez o uso dos filmes de polimetil - L - glutamato (PMG) orientado em aplicações piezoelétricas [26]. As pesquisas, entretanto, evoluíram com o advento dos modernos dielétricos com alta capacidade de retenção de carga, tais como o politetrafluoretileno (PTFE) e o polifluoreto de vinilideno (PVDF).

Os mais recentes exemplos de copolímeros são os fluorpolímeros amorfos (Teflon AF) e o hexafluorpropileno (HFP), que demonstraram bom desempenho térmico e coeficientes de piezeletricidade compatíveis com os materiais anteriormente empregados.

Além desses, outros materiais estão sendo estudados com resultados satisfatórios de piezo e piroeletricidade [27], como os polímeros silicinados, os fluoretados e as poliamidas aromáticas. 


\subsection{PIEZOELETRICIDADE DOS POLÍMEROS POROSOS}

No início dos anos 1970, Hayakawa e Wada [28, 29, 30] apresentaram uma teoria para explicar a piezo ou a termoeletricidade dos eletretos de cargas espaciais, não vinculadas aos eletrodos, quando submetidos a deslocamentos por compressão ou expansão. Na mesma época, as propriedades de piezo e de piroeletricidade foram observadas por Lewiner et al. [31] em polipropilenos não polares (PP). Como os coeficientes piezoelétricos não apresentavam valores significativos, novas pesquisas adicionais foram fortemente incentivadas.

Somente em meados da década seguinte, nos anos oitenta, foi apresentado, na Finlândia, um novo tipo de filme de PP bastante poroso, com características similares àquelas apresentadas na figura 2.6. Desde então, as propriedades piezoelétricas do chamado filme PP eletromecânico [31] têm sido investigadas, e coeficientes piezoelétricos até $300 \mathrm{pC} / \mathrm{N}$ foram possíveis de alcançar. Esses materiais, no entanto, apresentam o inconveniente de grande instabilidade térmica.

A produção dos filmes de polipropileno celulares - PP se dá através da modificação do processo de extrusão ventilada. Antes da ventilação do filme, bolhas esféricas com diâmetro aproximado de $10 \mu \mathrm{m}$ são formadas, geralmente pela injeção de gás durante a fundição do polímero. $\mathrm{O}$ material fundido é extrudado em um tubo resfriado em sua parte inferior e reaquecido por ventilação em sua parte superior. A formação do filme é acompanhada de orientação biaxial, o que resulta em discos ou lentes, com diâmetros superiores a $10 \mu \mathrm{m}$ e espessura da ordem de $1 \mu \mathrm{m}$ [32]. 


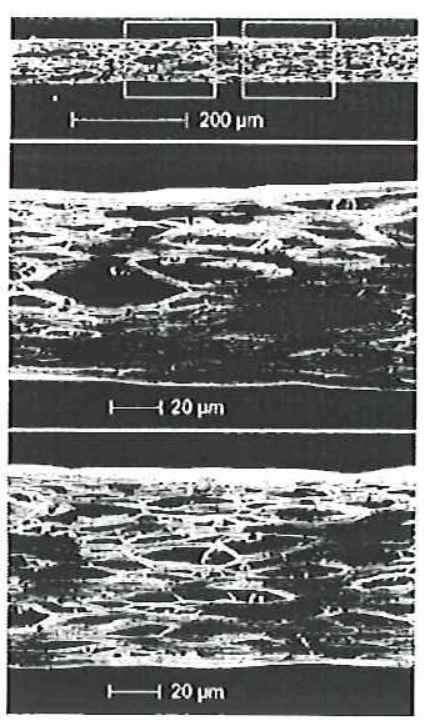

Figura 2.6-Imagem de corte transversal feito em um filme Celular PP de 70 um em duas posições (centro e inferior) feita com um microscópio SEM.

Os filmes são produzidos com espessuras de 40, 80 e $160 \mu \mathrm{m}$, estrutura fibrosa com poros abertos e índice de porosidade próximo a 50\% pelo Shanghai Plastics Institute, e permitem, ainda, serem carregados pelos métodos conhecidos.

\subsection{PIEZOELETRICIDADE EM POLÍMEROS CELULARES}

Após as descobertas de Eguchi e de suas experiências com eletretos feitos com cera de carnaúba, a inovação se acelerou com o uso dos dielétricos de polímeros para a obtenção dos mesmos produtos, em particular com a descoberta da boa retenção de cargas elétricas dos compostos de politetrafluoretileno (PTFE) e de polifluoreto de vinilideno (PVDF), nos anos 1960 e 1970, respectivamente.

Ao mesmo tempo foram desenvolvidos pelas indústrias outros tipos de materiais com os mesmos compostos, porém com características físicas específicas, como os polímeros celulares e os porosos. 
O filme celular PP é muito bem aceito como polímero piezelétrico e admitido em várias aplicações [33]. Este tipo de polímero apresenta em sua estrutura células semelhantes a lentes bicôncavas, preenchidas com gás, similares àquelas ilustradas na figura 2.7. O carregamento elétrico dessas células se faz promovendo-se a separação das cargas elétricas internas a elas, de tal forma que o resultado final fique como mostra a figura 2.8. Esta separação de cargas forma o eletreto e assegura as propriedades piro e piezelétricas deste polímero.

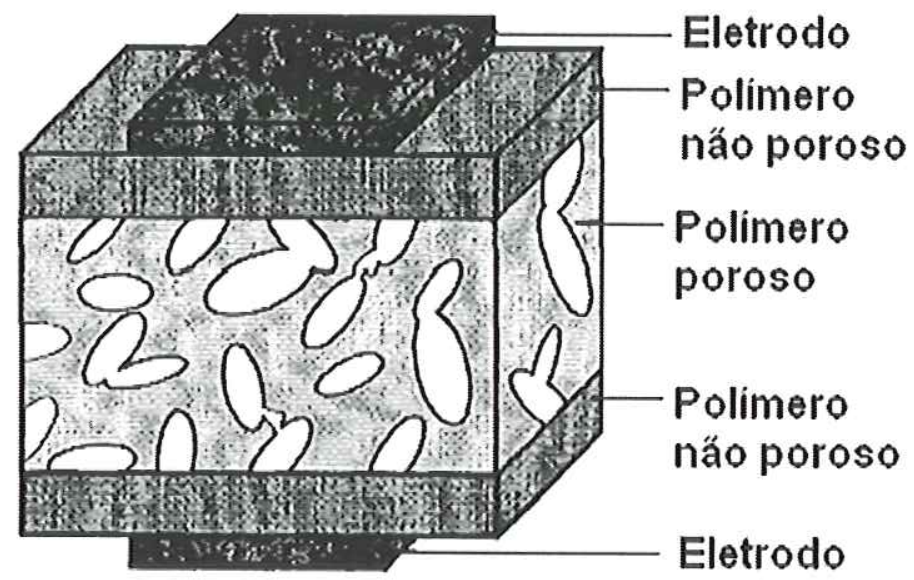

Figura 2.7-Estrutura esquemática do filme poroso, mostrando as cavidades internas em forma de lentes bicôncavas.

Hoje, o carregamento elétrico usual consiste no processo por descargas corona sobre o filme celular PP. A atividade piezelétrica observada é proporcional ao potencial de superfície resultante, função da corrente corona aplicada.

As cargas elétricas no interior das células adquirem uma polarização mensurável, ou seja, de constante piezelétrica significativa, quando a tensão corona ultrapassa os valores de limiar de ruptura. Neste caso, os coeficientes piezelétricos podem atingir valores de $250 \mathrm{pC} / \mathrm{N}$ em filme de $70 \mu \mathrm{m}$ de espessura $[34,38]$. Valores 
ainda maiores, de até $790 \mathrm{pC} / \mathrm{N}$, podem ser atingidos quando se usa tratamento especial com gás, antes ou durante as descargas corona.

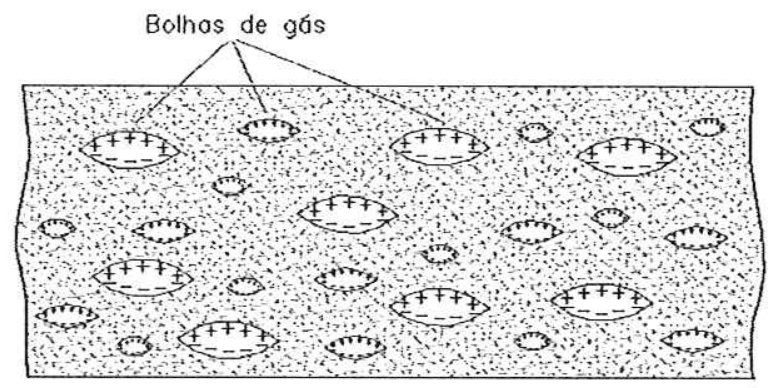

Moterial Dielétrico

Figura 2.8 - Estrutura esquemática do filme poroso, mostrando as cavidades internas em forma de lentes bicôncavas com os carregamentos.

O recente interesse no carregamento permanente de filmes de polímeros com estrutura celular, ou porosa, aumentou, dadas as atrativas características que eles apresentam. Os filmes de polipropileno (PP), de politetrafluoretileno (PTFE) e de dióxido de silício $\left(\mathrm{SiO}_{2}\right)$ apresentam excelente comportamento como eletreto quando carregados por meio de qualquer método conhecido. Eles apresentam propriedades piezoelétricas e constantes piezoelétricas comparáveis com as encontradas nas cerâmicas, com a vantagem de melhor comportamento mecânico, o que lhes permite uma maior possibilidade de aplicações.

\subsection{POLÍMEROS CELULARES CARREGADOS POR TENSÕES IMPULSIVAS}

O método de carregamento de polímeros por descargas corona é aplicado em sistemas de eletrofotografia e de carregamento de eletretos. No caso dos eletretos, é bastante utilizado, apesar de apresentar alguns inconvenientes: os materiais para serem 
carregados necessitam ser submetidos a tensões elevadas por períodos muito longos e apresentam dificuldade de controle das cargas depositadas na superfície irradiada [35, 39]. Mesmo com os arranjos idealizados para a melhora do rendimento, como o triodo corona, continuam ocorrendo inconvenientes.

Outra forma de carregamento elétrico nos polímeros celulares PP intensamente estudado é a aplicação de pulsos de alta tensão de curta duração nas faces metalizadas do filme através de eletrodos de contato.

Um arranjo elétrico possibilita montar um circuito de forma que as faces do filme de dielétrico previamente metalizadas recebam os terminais de um gerador de alta tensão com capacidade de fornecer tensões impulsivas.

A figura 2.9 mostra, de forma esquemática, a forma do circuito elétrico e a forma da curva de tensão de impulso desejada, fornecida pelo gerador. Os valores de tensão e dos tempos de subida e de decrescimento da tensão podem ser alterados de forma a obter resultados diferentes de carregamento do eletreto.

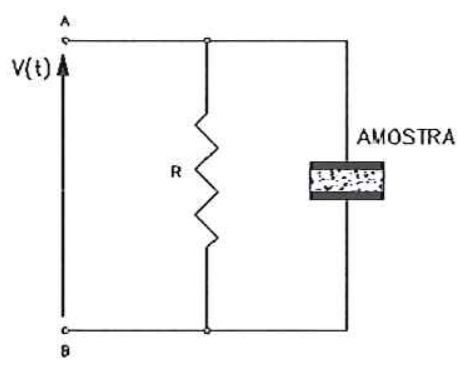

(a)

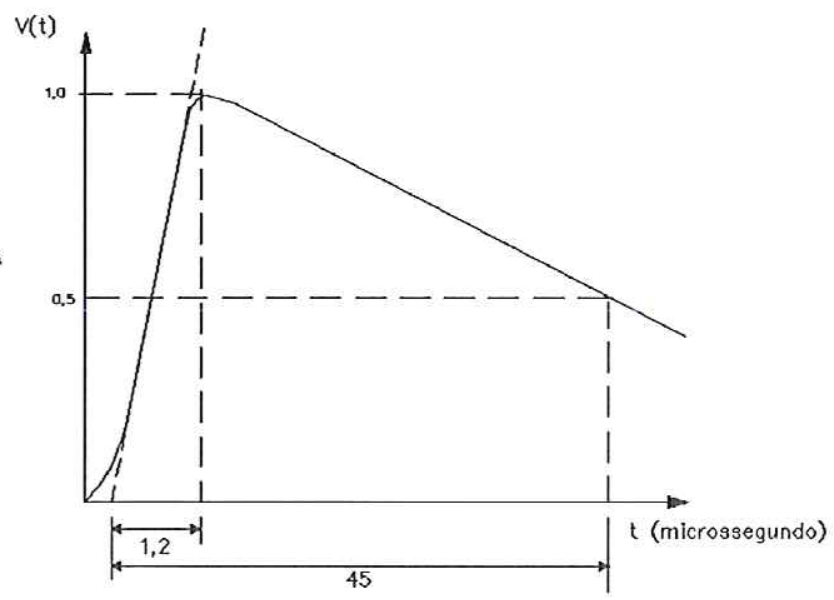

(b)

Figura 2.9 - (a) Mostra o circuito elétrico com o gerador de impulso e a amostra e (b) Mostra as características da curva de tensão de impulso. 
O carregamento do material dielétrico se dá quando o valor da tensão fornecida pelo gerador cresce de um valor $\mathrm{V}_{\mathrm{g}}(\mathrm{t})$ no interstício até o valor crítico $\mathrm{V}_{\mathrm{c}}$ [9] quando, então, é produzida uma descarga eletrônica que é transferida do eletrodo para o interior do material dielétrico, ficando, dessa forma, criado o eletreto. 


\title{
CAPÍTULO III \\ SENSOR PIEZOELÉTRICO DE TEFLON FEP
}

\author{
Neste capítulo, além da idealização do sensor \\ piezoelétrico, também serão discutidos todos os \\ procedimentos experimentais para poder obtê-lo.
}

\subsection{IDEALIZAÇÃO DO SENSOR PIEZOELÉTRICO}

O sensor piezoelétrico objeto desta pesquisa, foi idealizado com base no trabalho de Altafim e outros [9], quando idealizaram o eletreto por descargas impulsivas. Nesse trabalho, foi mostrado que eletretos podiam ser formados por aplicação de tensões impulsivas em uma configuração composta por um dielétrico entre dois eletrodos. Criando-se interstícios de ar, entre o filme dielétrico - no caso o Teflon FEP - e o eletrodo, pôde-se obter um carregamento elétrico homogêneo de amostras, formando eletretos em curtos espaços de tempo, da ordem de microssegundos. Esse processo de formação de eletretos também se mostrou adequado quando foi usado no carregamento de dielétricos celulares e porosos [34]. Durante os experimentos realizados para esse trabalho [34], pôde-se intuir que o fenômeno do carregamento elétrico dos dielétricos porosos e celulares, ou seja, aqueles contendo microcavidades ou microbolhas, assemelhava-se, e muito, ao carregamento por descargas impulsivas, com eletrodos tendo microcavidades.

Como os dielétricos porosos são de difícil aquisição, por não estarem ainda em estágio comercial e também por apresentarem, muitas vezes, sigilo tecnológico, a continuidade das pesquisas, no Brasil, com esses materiais torna-se, com freqüência, impossível. Soma-se a este problema o fato de que o controle do processo de seu 
carregamento é extremamente complicado, em razão da heterogeneidade das formas e quantidades das cavidades ou microbolhas. Em um processo comercial, o ajuste dos valores das tensões de carregamento para obter um mesmo valor dos coeficientes piezoelétricos pode tornar-se impraticável.

Esses dois problemas fizeram surgir a necessidade de desenvolver uma metodologia alternativa que tornasse o Brasil menos dependente das tecnologias internacionais e que também facilitasse a produção serial de sensores piezoelétricos através de um melhor controle das tensões de carregamento. Isso foi conseguido com a nova metodologia de preparação de amostra, cerne deste trabalho, e mais bem detalhada nos itens subseqüentes.

\subsection{NOVA METODOLOGIA PARA PREPARAÇÃO DE AMOSTRAS}

O eletreto para ser formado deve passar por etapas que compreendem a escolha do dielétrico, a implantação dos eletrodos - que servirão tanto para o carregamento quanto para posteriores terminais - a criação de interstícios de ar com dimensões uniformes e o carregamento elétrico propriamente dito.

\subsubsection{ESCOLHA DO MATERIAL}

O material dielétrico escolhido para este trabalho foi o Teflon FEP, fabricado pela DUPONT, com espessura de $80 \mu \mathrm{m}$. Outras espessuras também podem ser usadas, contudo esta espessura, em particular, apresenta uma excelente resistência mecânica ao cisalhamento, dificultando o processo de rasgadura. 
Entretanto, a principal razão para a escolha do material supracitado foi seu longo tempo de decaimento, superior a 500 anos [8, 19]. Amostras de Teflon FEP carregadas e mantidas em ambientes isolados demoram até 500 anos para descarregar.

\subsubsection{IMPLANTAÇÃO DOS ELETRODOS}

Os critérios para a escolha da implantação dos eletrodos nos filmes de Teflon FEP foram os de maior simplicidade e os de menor preço. Inicialmente, adotou-se o mesmo processo usado na fabricação de capacitores industriais. Essa técnica, contudo, mostrou-se inadequada, por duas razões. A primeira é que ela torna as amostras não flexíveis devido à grande espessura da camada de alumínio depositada sobre os filmes; e a segunda é que a camada de alumínio injetada não apresenta boa aderência e solta-se com muita facilidade do Teflon FEP.

A técnica de deposição de alumínio em vácuo sobre os eletrodos foi a que prevaleceu. Essa técnica, embora muito mais cara, assegura uma perfeita aderência e também ótima flexibilidade.

Outra técnica paliativa que foi empregada e que serviu como técnica laboratorial foi a de fixar lâminas de alumínio com espessura de $100 \mu \mathrm{m}$ com verniz aspergido sobre a amostra, mais bem detalhada no item subseqüente.

\subsubsection{METODOLOGIA PARA CONFECÇÃO DAS AMOSTRAS}

As amostras do sensor piezoelétrico foram confeccionadas recortando-se o Teflon FEP em círculos com diâmetro de $5 \mathrm{~cm}$ (área de 19,64 $\mathrm{cm}^{2}$ ). Com o uso de bastidores de alumínio, esses círculos foram esticados e limpos com o uso de álcool etílico nelas borrifado. A limpeza com o álcool etílico, além de facilitar o processo de colagem, também promove o descarregamento elétrico da amostra. Normalmente, todos 
os filmes virgens apresentam-se carregados, em função de seu processo de fabricação e de seu enrolamento.

Terminada a limpeza e a secagem do álcool, as amostras foram submetidas à vaporização de verniz comercial e, em seguida, unidas duas a duas.

Da mesma forma, também foram unidos às superficies externas das duas lâminas de Teflon FEP círculos recortados de lâmina de alumínio, também de uso comercial, e espessura de $100 \mu \mathrm{m}$, com diâmetro aproximado de $3 \mathrm{~cm}$ (área aproximada de $7 \mathrm{~cm}^{2}$ ). Esses círculos metálicos foram utilizados como eletrodos e como contatos elétricos do sensor (Foto 3.1).

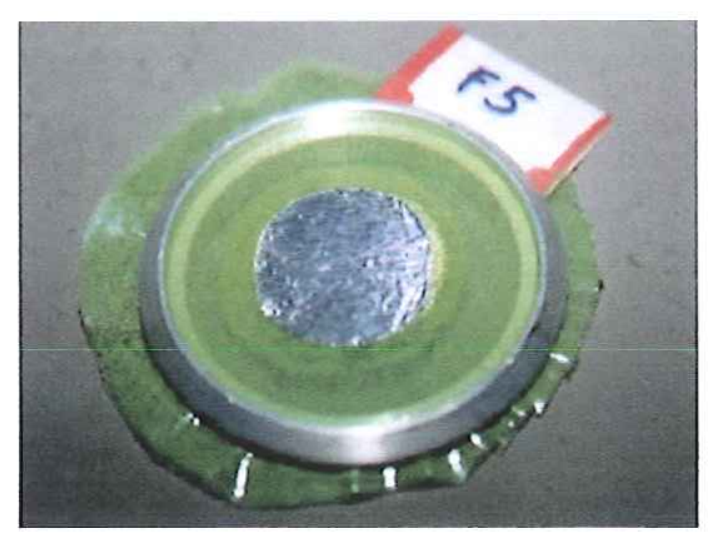

Foto 3.1 - Amostra de Teflon FEP com duas laminas em bastidor de aluminio e eletrodos unidos por verniz e preparada para o carregamento com tensão impulsiva.

Na figura 3.1, encontra-se ilustrada uma representação expandida da amostra. Detalhe importante desse processo de confecção das amostras é que elas mostraram-se flexíveis, mecanicamente resistentes e, com o uso do verniz borrifado sobre a amostra de forma homogênea, obteve-se, além da união e fixação dos filmes de Teflon FEP e das lâminas de alumínio, a formação de interstícios de ar com espessura da ordem de 10 $\mu \mathrm{m}$. Esses interstícios, embora com áreas distintas, possuem uma espessura muito homogênea, permitindo um melhor controle do processo de carregamento. 


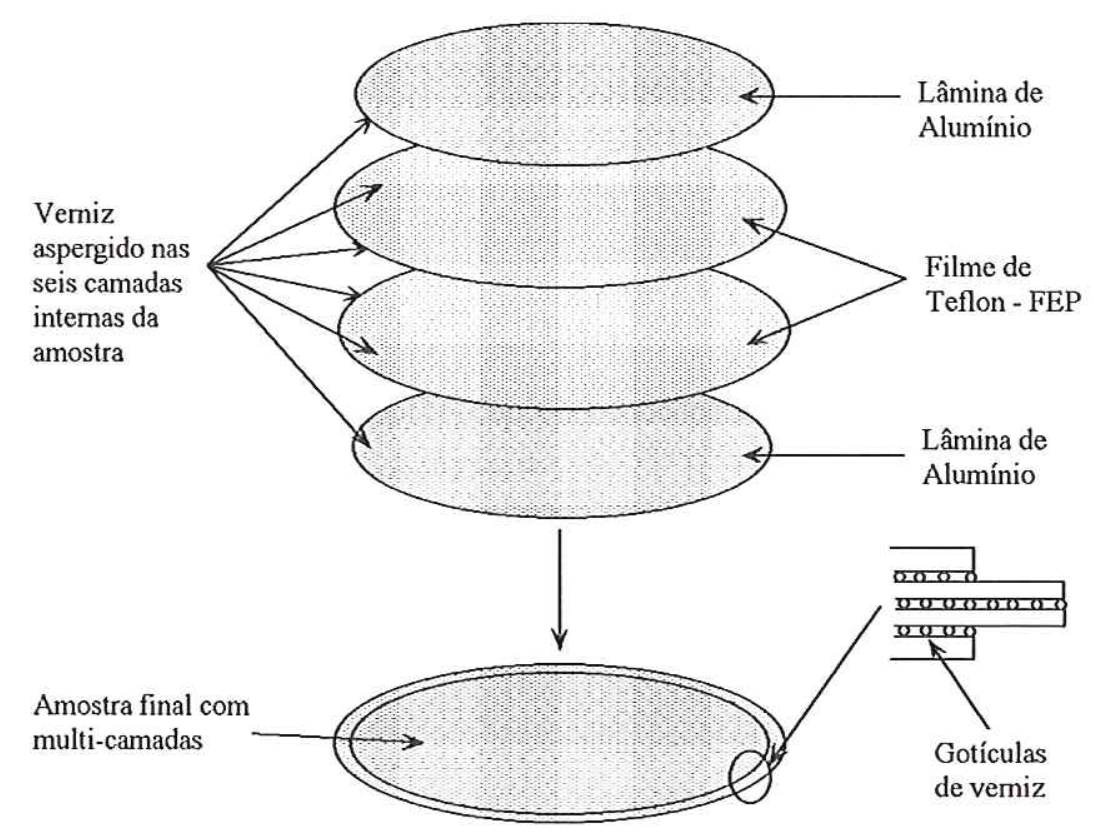

Figura 3.1 - Mostra a forma construtiva das amostras e a disposição das lâminas de Teflon FEP e dos eletrodos de alumínio.

\subsection{CARREGAMENTO DAS AMOSTRAS}

As amostras preparadas como indicado no item anterior foram carregadas eletricamente pelo processo de descarga impulsiva com o uso de um gerador de impulso Marx, que fornece uma tensão impulsiva dada pela equação:

$$
v(t)=v_{0}\left(e^{-\alpha_{1} \cdot t}-e^{-\alpha_{2} \cdot t}\right)
$$

onde $\mathrm{v}_{0}$ é a tensão de pico, e $\alpha_{1}$ e $\alpha_{2}$ são constantes de tempo.

O circuito elétrico adotado para o carregamento encontra-se na Figura 3.2, e consta de um capacitor $\mathrm{C}_{1}$ de $1,35 \mathrm{mF}$, conectado em série com o centelhador de ar $\mathrm{G}$ e 
o resistor $R_{2}$ de $44 \Omega$. Em paralelo ao resistor $R_{2}$, e em série com o capacitor $C_{2}$ de 11 $\mathrm{nF}$, está conectado o resistor $\mathrm{R}_{1}$ de $72 \Omega$ (Foto 3.2 ).

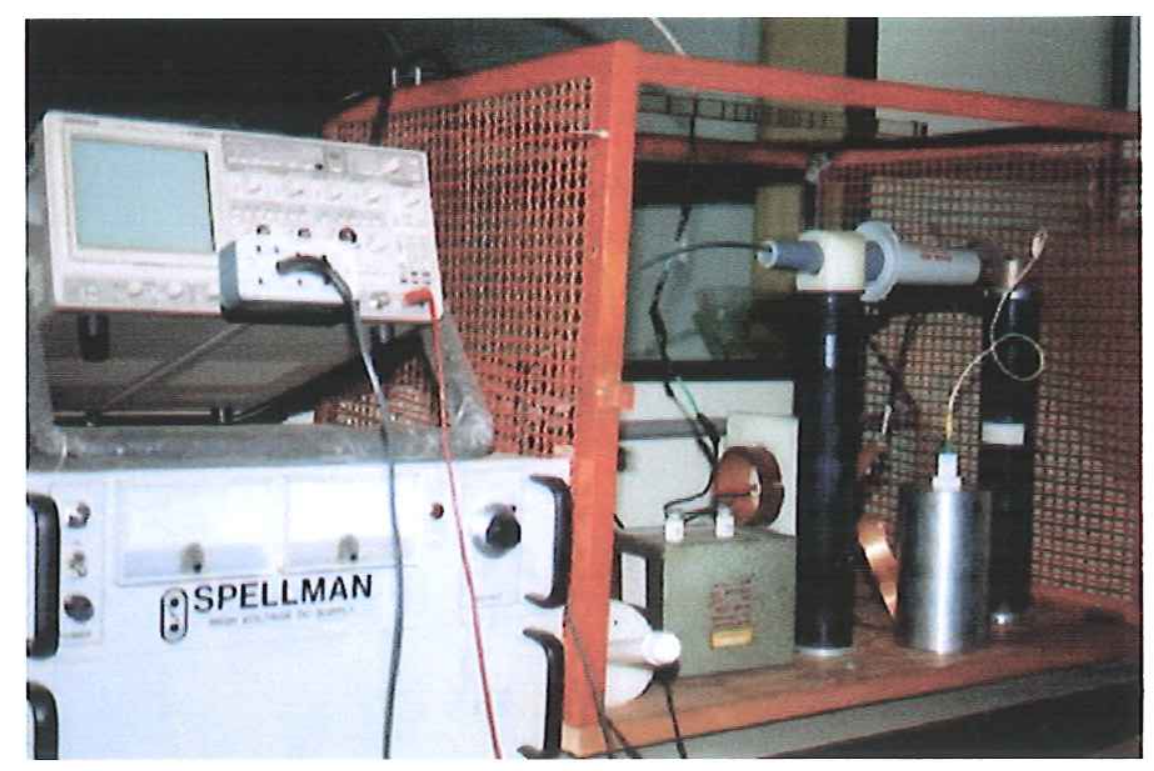

Foto 3.2 - Equipamento e circuito de carregamento por tensões impulsivas.

Os capacitores são carregados negativamente por uma fonte de tensão Spellmam - High Voltage DC Supply-20kV com tensão de até - $12,5 \mathrm{kV}$. Fixando-se as constantes de tempo $\alpha_{1}$ e $\alpha_{2}$, da equação (3.1), pôde-se obter formas de ondas com frentes iguais a $1,2 \mu \mathrm{s}$ e de tempos de meia onda iguais a $45 \mu \mathrm{s}$. Os tempos de meia onda são medidos entre o início da onda e o tempo em que a tensão decai metade de seu valor de crista. 


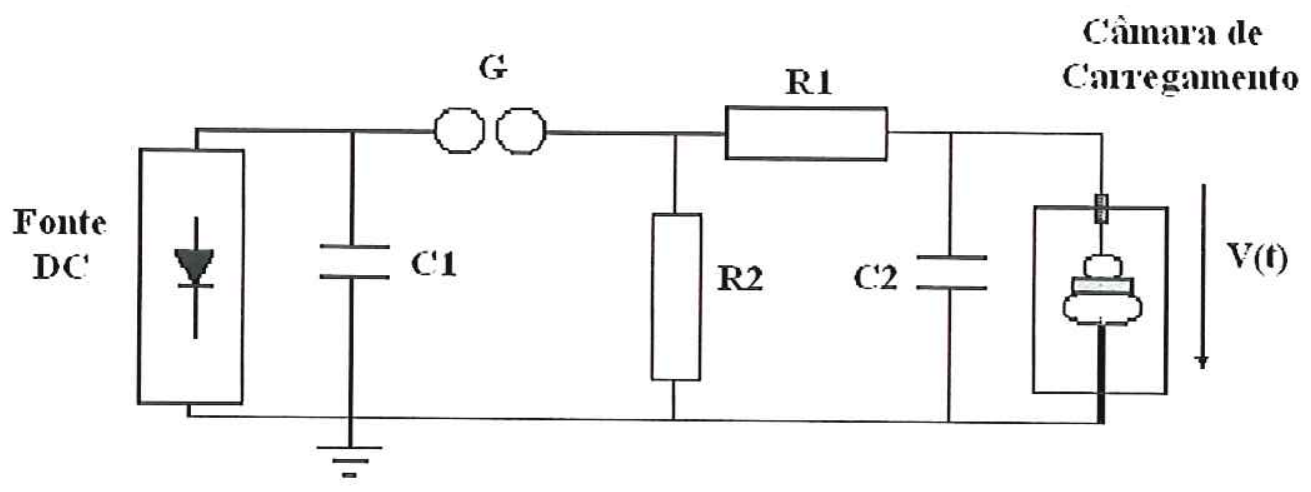

Figura 3.2 - Circuito de ensaio usado no carregamento das amostras. Sendo $R_{1}=72 \Omega, R_{2}=$ $44 \Omega, C_{1}=1,35 \mathrm{mF}$ e $C_{2}=11 n F$.

A câmara de carregamento é composta de um tubo cilíndrico de alumínio fundido onde estão conectados os dois eletrodos eletricamente isolados. Durante os ensaios, o eletrodo inferior foi devidamente aterrado, e o superior conectado à fonte de alta tensão.

No interior do cilindro de alumínio, esses eletrodos também fixam as amostras. Tendo o eletrodo inferior diâmetro de $4 \mathrm{~cm}$ e o superior diâmetro de $3 \mathrm{~cm}$, dificultam a formação de descargas elétricas laterais durante o processo de carregamento.

Completa o circuito um divisor de tensão Tektronix 605 (1000:1) conectado a um osciloscópio digital KIKUSUI 7101 A - $100 \mathrm{MHz}$. Esses elementos fornecem condições para que as tensões impulsivas sejam medidas.

Todos os carregamentos das amostras foram feitos em condições ambientais, com a temperatura a $25^{\circ} \mathrm{C}$, a umidade relativa do ar a $55 \%$ e a pressão atmosférica a $690 \mathrm{mmHg}$. 


\subsection{MEDIÇÃO DOS COEFICIENTES PIEZOELÉTRICOS}

Após o carregamento das amostras, seus coeficientes piezoelétricos foram determinados pela metodologia descrita nas referências [35, 36, 37]. Ela encontra-se esquematizada na figura 3.3 .

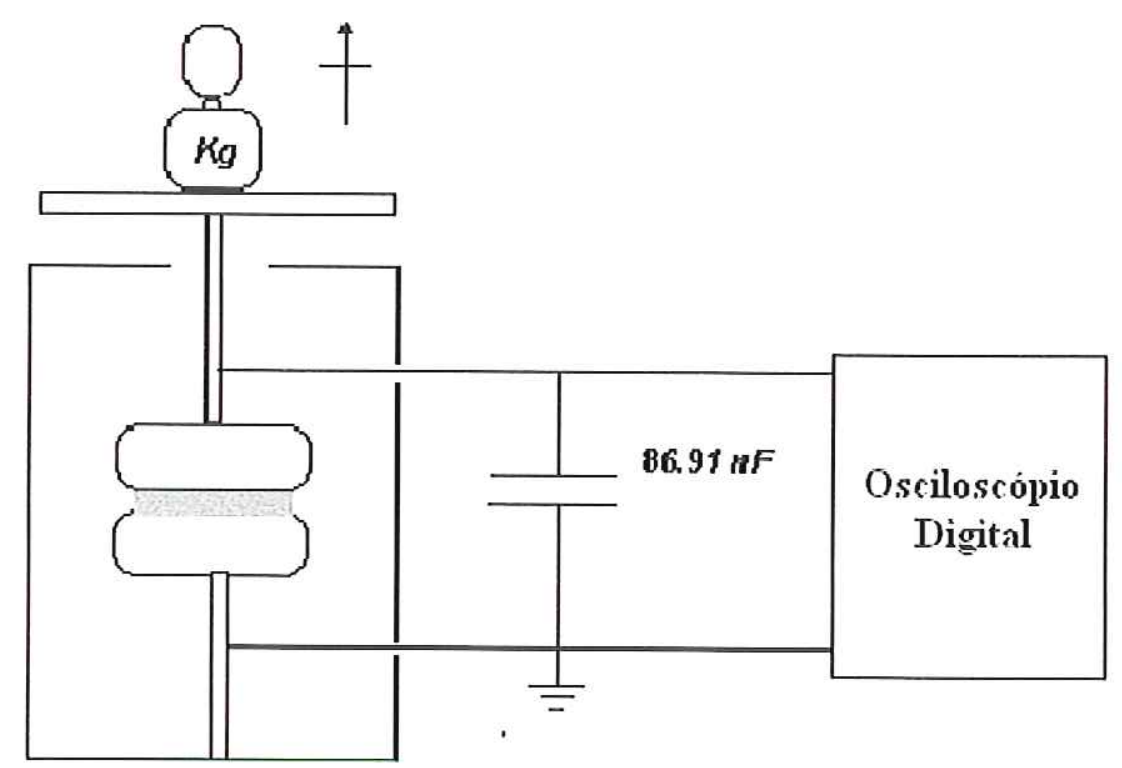

Figura 3.3 - Arranjo para a medição do coeficiente piezoelétrico.

Nesse arranjo, as amostras são colocadas no interior de um compartimento metálico aterrado, que contém uma base fixa e um embolo móvel sobre o qual são colocados pesos.

Entre os terminais ligados à base fixa e o embolo móvel, foi conectado um capacitor de $86,91 \mathrm{nF}$ em paralelo, cujos terminais foram ligados a um osciloscópio digital Hewllet Packard modelo-5461B (Foto 3.3). 


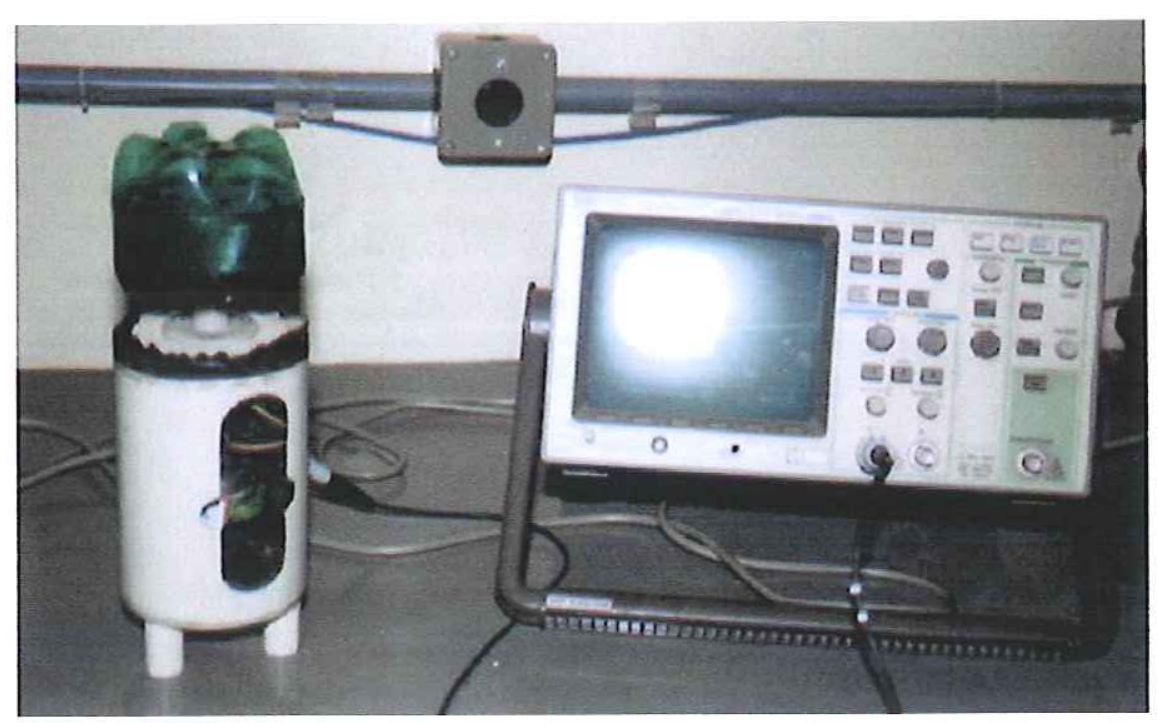

Foto 3.3 - Equipamento e circuito de medida.

Nesse arranjo, por exemplo, quando um esforço de descompressão de $20 \mathrm{~N}$ foi aplicado sobre uma amostra carregada com uma tensão de pico negativo de $12,0 \mathrm{kV}$, pôde-se detectar o sinal apresentado na figura 3.4 .

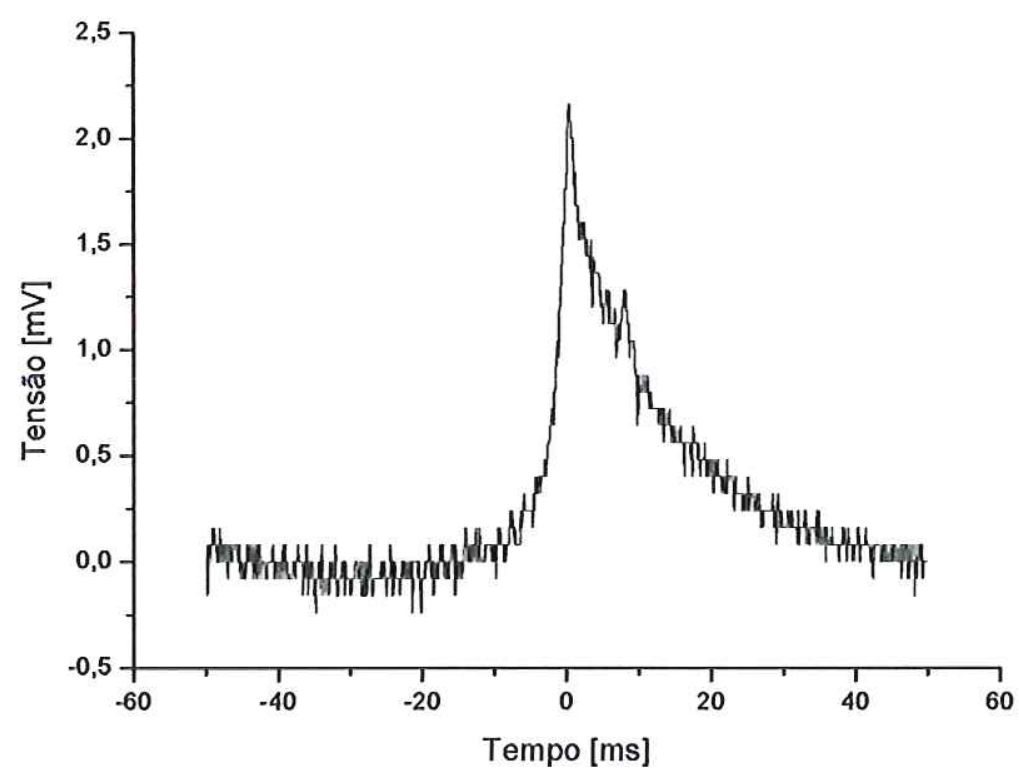

Figura 3.4 - Medição em osciloscópio da tensão gerada por uma amostra quando submetida a uma descompressão de $20 \mathrm{~N}$. 
Durante os ensaios, para garantir que os esforços mecânicos fossem uniformemente distribuidos em toda a amostra, foi colocada em sua parte superior um círculo de borracha condutiva de $3 \mathrm{~cm}$ de diâmetro e $3 \mathrm{~mm}$ de espessura. Dessa forma, além de garantir os contatos entre a amostra e os terminais de medição, mantêm-se os esforços mecânicos uniformemente distribuídos sobre a amostra.

Usando-se o mesmo arranjo elétrico e os mesmos equipamentos de medição, a curva se altera, e os resultados são diferentes quando o mesmo peso de $20 \mathrm{~N}$ é aplicado à mesma amostra, porém na forma de compressão, como podemos verificar pela figura 3.5. Isso se deve à dificuldade em se controlar manualmente o impacto do peso sobre os eletrodos no processo de compressão.

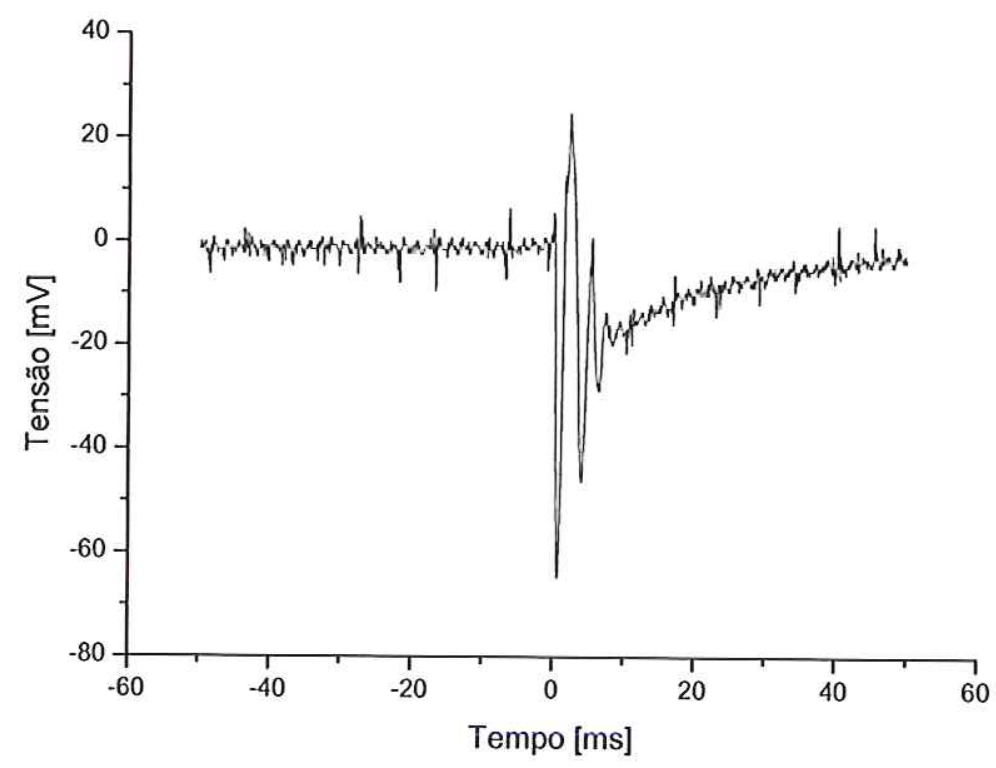

Figura 3.5 - Medição em osciloscópio feita na compressão da amostra quando submetida a uma carga de $20 \mathrm{~N}$ na direção vertical. 


\subsection{RESULTADOS ALCANÇADOS}

Após o carregamento das amostras com diferentes picos de tensão negativa variando de $1,97 \mathrm{kV}$ a $12 \mathrm{kV}$, foram feitas as medições das cargas elétricas encontradas nas amostras e o cálculo do coeficiente piezelétrico $\mathrm{d}_{33}$, conforme se pode visualizar nas tabelas apresentadas a seguir.

Tabela 1 - Medições das tensões nas amostras - descompressão.

\begin{tabular}{|c|c|c|c|c|c|c|c|}
\hline Amostras & C1 & $\mathrm{C2}$ & $\mathrm{C}^{*}$ & $\mathrm{C} 4$ & C5 & C6 & $\mathrm{C}^{*}$ \\
\hline $\begin{array}{c}\text { Tensão de } \\
\text { Carregamento da } \\
\text { amostra [kV] }\end{array}$ & 6,20 & 6,20 & 6,20 & 8,14 & 8,14 & 9,60 & 9,60 \\
\hline Medidas efetuadas & {$[\mathrm{mV}]$} & {$[\mathrm{mV}]$} & {$[\mathrm{mV}]$} & {$[\mathrm{mV}]$} & {$[\mathrm{mV}]$} & {$[\mathrm{mV}]$} & {$[\mathrm{mV}]$} \\
\hline 1 & 38,00 & 36,00 & 32,50 & 44,00 & 66,25 & 58,75 & 74,37 \\
\hline 2 & 36,00 & 30,00 & 30,60 & 45,62 & 56,87 & 43,75 & 60,00 \\
\hline 3 & 28,00 & 24,00 & 33,00 & 45,62 & 62,50 & 28,13 & 46,88 \\
\hline 4 & 24,00 & 19,00 & 30,70 & 31,88 & 51,25 & 28,10 & 43,75 \\
\hline 5 & 18,00 & & 23,70 & 28,13 & 33,13 & 27,50 & 40,00 \\
\hline 6 & 18,00 & & & 34,38 & 28,13 & 28,75 & 37,50 \\
\hline 7 & & & & 18,75 & 30,00 & 25,00 & 35,63 \\
\hline 8 & & & & 16,25 & 30,00 & 22,50 & 24,38 \\
\hline 9 & & & & 23,75 & 26,25 & 25,00 & 29,38 \\
\hline 10 & & & & 21,25 & 34,38 & 26,87 & 35,00 \\
\hline 11 & & & & 25,00 & 36,88 & 20,62 & 27,50 \\
\hline 12 & & & & 24,38 & 30,00 & 22,50 & 29,38 \\
\hline 13 & & & & 24,30 & 26,87 & & 32,50 \\
\hline 14 & & & & 20,00 & 28,13 & & 32,50 \\
\hline 15 & & & & 17,50 & 32,50 & & 26,25 \\
\hline 16 & & & & 22,50 & & & 25,63 \\
\hline 17 & & & & 24,38 & & & \\
\hline $\begin{array}{c}\text { Média das } 3 \\
\text { últimas medidas }\end{array}$ & 20,00 & 24,33 & 29,13 & 21,46 & 29,17 & 23,33 & 28,13 \\
\hline $\begin{array}{c}\text { Média das } \\
\text { tensões de } \\
\text { carregamento } \\
\text { iguais }\end{array}$ & \multicolumn{3}{|c|}{24,49} & \multicolumn{2}{|c|}{25,31} & \multicolumn{2}{|c|}{25,73} \\
\hline
\end{tabular}


O cálculo do coeficiente piezoelétrico pode ser obtido por

$$
d_{33}=\frac{C V}{P}
$$

onde $\mathrm{C}$ é o valor da capacitância em nF, $\mathrm{V}$ é o valor da tensão obtida nas medições em $\mathrm{mV}$, e $\mathrm{P}$ é o valor da carga em $\mathrm{N}$.

Tabela 2 - Cálculo dos coeficientes de piezoeletricidade $\mathrm{d}_{33}$.

\begin{tabular}{|c|c|c|c|c|c|c|c|}
\hline & C1 & C2 & C3* & C4 & C5 & C6 & C7* \\
\hline $\begin{array}{c}\text { Tensão de } \\
\text { Carregamento } \\
\text { da amostra [kV] }\end{array}$ & 6,20 & 6,20 & 6,20 & 8,14 & 8,14 & 9,60 & 9,60 \\
\hline$n .^{\circ}$ & {$[\mathrm{pC} / \mathrm{N}]$} & {$[\mathrm{pC} / \mathrm{N}]$} & {$[\mathrm{pC} / \mathrm{N}]$} & {$[\mathrm{pC} / \mathrm{N}]$} & {$[\mathrm{pC} / \mathrm{N}]$} & {$[\mathrm{pC} / \mathrm{N}]$} & {$[\mathrm{pC} / \mathrm{N}]$} \\
\hline 1 & 161,08 & 152,60 & 137,77 & 186,51 & 280,83 & 249,04 & 315,25 \\
\hline 2 & 152,60 & 127,17 & 129,71 & 193,38 & 241,07 & 185,45 & 254,34 \\
\hline 3 & 118,69 & 101,74 & 139,89 & 193,38 & 264,94 & 119,24 & 198,72 \\
\hline 4 & 101,74 & 80,54 & 130,14 & 135,14 & 217,25 & 119,11 & 185,45 \\
\hline 5 & 76,30 & & 100,46 & 119,24 & 140,44 & 116,57 & 169,56 \\
\hline 6 & 76,30 & & & 145,74 & 119,24 & 121,87 & 158,96 \\
\hline 7 & & & & 79,48 & 127,17 & 105,97 & 151,03 \\
\hline 8 & & & & 68,88 & 127,17 & 95,38 & 103,35 \\
\hline 9 & & & & 100,68 & 111,27 & 105,97 & 124,54 \\
\hline 10 & & & & 90,08 & 145,74 & 113,90 & 148,36 \\
\hline 11 & & & & 105,97 & 156,33 & 87,41 & 116,57 \\
\hline 12 & & & & 103,35 & 127,17 & 95,38 & 124,54 \\
\hline 13 & & & & 103,01 & 113,90 & & 137,77 \\
\hline 14 & & & & 84,78 & 119,24 & & 137,77 \\
\hline 15 & & & & 74,18 & 137,77 & & 111,27 \\
\hline 16 & & & & 95,38 & & & 108,64 \\
\hline 17 & & & & 103,35 & & & \\
\hline $\begin{array}{c}\text { Média das } 3 \\
\text { últimas medidas }\end{array}$ & 84,78 & 103,15 & 123,50 & 90,97 & 123,64 & 98,89 & 119,23 \\
\hline $\begin{array}{c}\text { Média das } \\
\text { tensões de } \\
\text { carregamento } \\
\text { iguais }\end{array}$ & \multicolumn{3}{|c|}{103,81} & \multicolumn{2}{|c|}{107,30} & \multicolumn{2}{|c|}{109,06} \\
\hline
\end{tabular}


As grandezas usadas nos cálculos foram: Massa $=2,090 \mathrm{~kg} ; \mathrm{g}=9,81 \mathrm{~ms}^{-1} ; \mathrm{C}=$ $6,9110 \mathrm{nF}$

A figura 3.6 mostra a curva que relaciona o coeficiente piezoelétrico com a tensão de pico de carregamento.

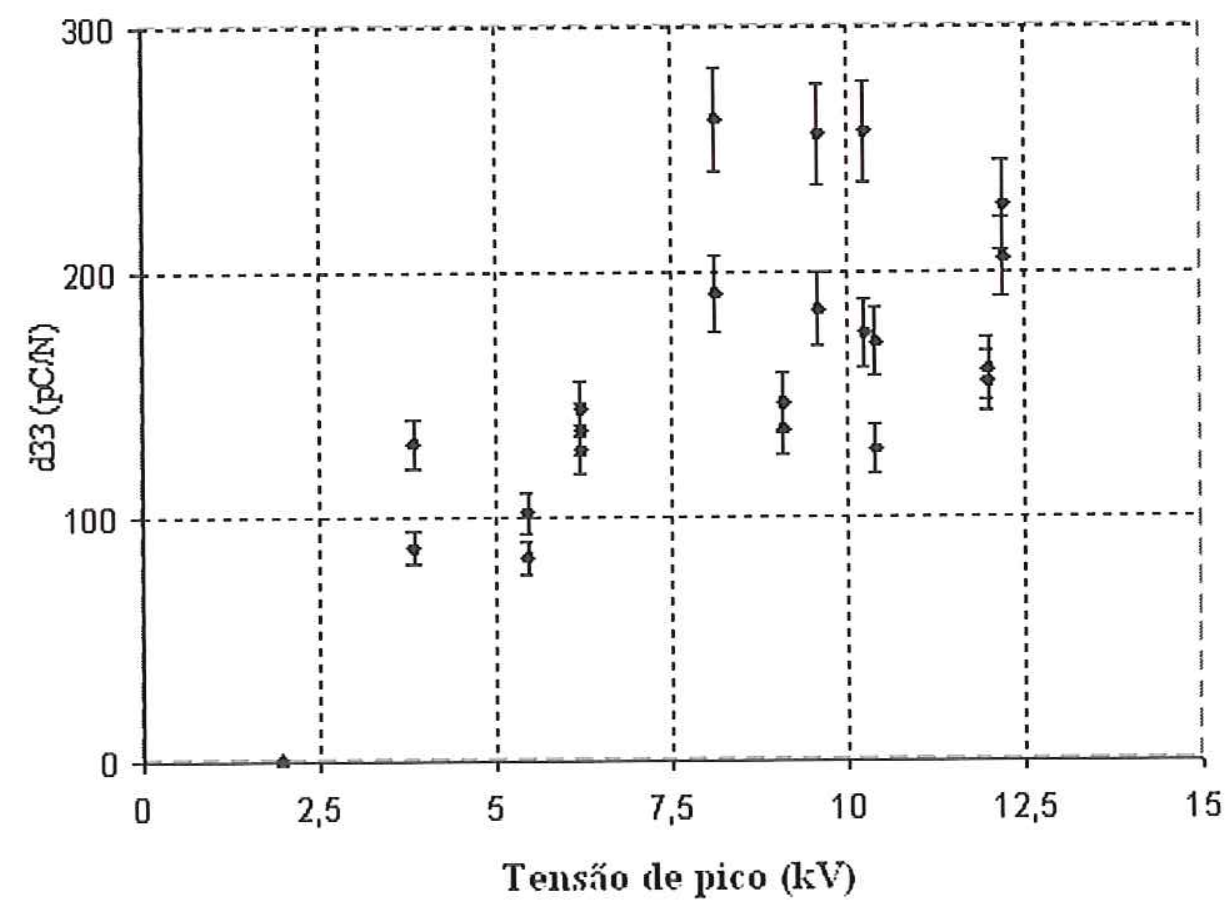

Figura 3.6 - Coeficiente piezoelétrico em função da tensão de impulso de carregamento.

Observa-se que a carga absorvida pelo dielétrico é tanto maior quanto maior é a tensão de impulso usada em seu carregamento, muito embora ocorra um valor ótimo por volta dos $10 \mathrm{kV}$ tornando a decair com tensões mais elevadas. Esse fato confirma estudos anteriores e é creditado ao processo de descarregamento das cavidades pelo fenômeno conhecido como "Back discharge de Paschen". 


\subsection{NOVOS RESULTADOS ALCANÇADOS}

Uma nova remessa de amostras foi confeccionada, manualmente, utilizando-se o mesmo processo anteriormente descrito em 3.2.3, e empregados os mesmos materiais. Essas amostras obtidas foram carregadas, também da mesma forma que as amostras anteriores e descritas no item 3.3, com tensões impulsivas variando de $2 \mathrm{kV}$ até $12 \mathrm{kV}$.

Após o carregamento, as amostras foram submetidas ao processo de medição de carga acumulada fazendo a descompressão de cargas mecânicas pelo processo descrito em 3.4, com pesos de $0,5 \mathrm{~N}$, partindo de $0,5 \mathrm{~N}$ até $12,5 \mathrm{~N}$.

Para cada um dos pesos aplicados, foram feitas cinco medições, e extraída a média aritmética. Uma parcela das amostras tem os resultados obtidos mostrados na tabela 3 e na tabela 4 , respectivamente: 
Tabela 3 - Medições das cargas (pC) nas amostras (descompressão) de lote de amostras

\begin{tabular}{|c|c|c|c|c|c|c|c|}
\hline & E 1 & E 4 & E 5 & E 6 & E 7 & F1 & F9 \\
\hline $\begin{array}{c}\text { Tensão de Carregamento da } \\
\text { amostra }[\mathrm{kV}]\end{array}$ & 9,10 & 10,40 & 12,00 & 12,00 & 3,85 & 5,83 & $2,3+t$ \\
\hline \multirow{5}{*}{ Somente Bandeja e Eletrodo } & 540 & 420 & 409 & 555 & 237 & 301 & 124 \\
\hline & 419 & 422 & 394 & 517 & 232 & 269 & 115 \\
\hline & 573 & 400 & 399 & 573 & 225 & 232 & 141 \\
\hline & 517 & 412 & 426 & 520 & 230 & 244 & 138 \\
\hline & 530 & 440 & 422 & 585 & 232 & 270 & 121 \\
\hline \multirow{5}{*}{ com Peso 1} & 1010 & 883 & 501 & 1140 & 545 & 687 & 218 \\
\hline & 1062 & 872 & 549 & 1144 & 541 & 643 & 245 \\
\hline & 942 & 896 & 550 & 1148 & 516 & 664 & 255 \\
\hline & 996 & 847 & 532 & 1160 & 549 & 675 & 226 \\
\hline & 1107 & 852 & 556 & 1134 & 555 & 675 & 228 \\
\hline \multirow{5}{*}{ com Peso 2} & 1278 & 1084 & 571 & 1340 & 712 & 822 & 291 \\
\hline & 1270 & 1090 & 587 & 1300 & 718 & 860 & 310 \\
\hline & 1225 & 1010 & 589 & 1320 & 698 & 896 & 304 \\
\hline & 1223 & 1105 & 596 & 1350 & 752 & 865 & 318 \\
\hline & 1172 & 1091 & 574 & 1352 & 708 & 896 & 323 \\
\hline \multirow{5}{*}{ com Peso 3} & 1145 & 1234 & 649 & 1300 & 821 & 1040 & 385 \\
\hline & 1287 & 1298 & 627 & 1331 & 878 & 1000 & 363 \\
\hline & 1191 & 1266 & 620 & 1339 & 795 & 1006 & 380 \\
\hline & 1252 & 1269 & 630 & 1329 & 795 & 1041 & 362 \\
\hline & 1199 & 1213 & 632 & 1370 & 856 & 1086 & 389 \\
\hline \multirow{5}{*}{ com Peso 4} & 1317 & 1400 & 640 & 1530 & 931 & 1240 & 420 \\
\hline & 1220 & 1428 & 662 & 1560 & 946 & 1250 & 418 \\
\hline & 1278 & 1469 & 685 & 1500 & 940 & 1238 & 416 \\
\hline & 1294 & 1405 & 684 & 1534 & 917 & 1285 & 419 \\
\hline & 1335 & 1439 & 674 & 1524 & 970 & 1280 & 430 \\
\hline \multirow{5}{*}{ com Peso 5} & 1350 & 1424 & 727 & 1588 & 1015 & 1336 & 466 \\
\hline & 1324 & 1500 & 718 & 1572 & 1090 & 1294 & 603 \\
\hline & 1220 & 1539 & 721 & 1518 & 1012 & 1320 & 553 \\
\hline & 1321 & 1458 & 755 & 1520 & 1000 & 1340 & 590 \\
\hline & 1200 & 1499 & 743 & 1750 & 1000 & 1250 & 584 \\
\hline \multirow{5}{*}{ com Peso 6} & 1388 & 1670 & 742 & 1730 & 1180 & 1380 & 555 \\
\hline & 1217 & 1639 & 798 & 1735 & 1096 & 1445 & 524 \\
\hline & 1222 & 1655 & 754 & 1724 & 1075 & 1340 & 559 \\
\hline & 1300 & 1590 & 770 & 1794 & 1079 & 1334 & 586 \\
\hline & 1311 & 1657 & 743 & 1660 & 1062 & 1360 & 530 \\
\hline \multirow{5}{*}{ com Peso 7} & 1320 & & 800 & & 1041 & & 556 \\
\hline & 1250 & & 853 & & 1115 & & 524 \\
\hline & 1300 & & 817 & & 1032 & & 526 \\
\hline & 1250 & & 831 & & 1033 & & 544 \\
\hline & 1218 & & 827 & & 1116 & & 553 \\
\hline
\end{tabular}


Tabela 4 - Médias dos valores encontrados nas medições das cargas (pC) nas amostras (descompressão) parcela de amostras

\begin{tabular}{|c|c|c|c|c|c|c|c|}
\cline { 2 - 8 } \multicolumn{1}{c|}{} & E 1 & E 4 & E 5 & E 6 & E 7 & F1 & F9 \\
\hline $\begin{array}{c}\text { Tensão de Carregamento } \\
\text { da amostra [kV] }\end{array}$ & 9,10 & 10,40 & 12,00 & 12,00 & 3,85 & 5,83 & 2,34 \\
\hline Bandeja & 515,8 & 418,8 & 410 & 550 & 231,2 & 263,2 & 127,8 \\
\hline Com Peso 1 & 1023,4 & 870 & 537,6 & 1145,2 & 541,2 & 668,8 & 234,4 \\
\hline Com Peso 2 & 1233,6 & 1076 & 583,4 & 1332,4 & 717,6 & 867,8 & 309,2 \\
\hline Com Peso 2 & 1214,8 & 1256 & 631,6 & 1333,8 & 829 & 1034,6 & 375,8 \\
\hline Com Peso 4 & 1288,8 & 1428,2 & 669 & 1529,6 & 940,8 & 1258,6 & 420,6 \\
\hline Com Peso 5 & 1283 & 1484 & 732,8 & 1589,6 & 1023,4 & 1308 & 559,2 \\
\hline Com Peso 6 & 1287,6 & 1642,2 & 761,4 & 1728,6 & 1098,4 & 1371,8 & 550,8 \\
\hline Com Peso 7 & 1267,6 & & 825,6 & & 1067,4 & & 540,6 \\
\hline
\end{tabular}

Esses dados nos permitem construir as curvas características da carga elétrica acumulada em função da carga mecânica aplicada na descompressão, para cada nível de tensão de carregamento, conforme se pode ver na figura 3.7 .

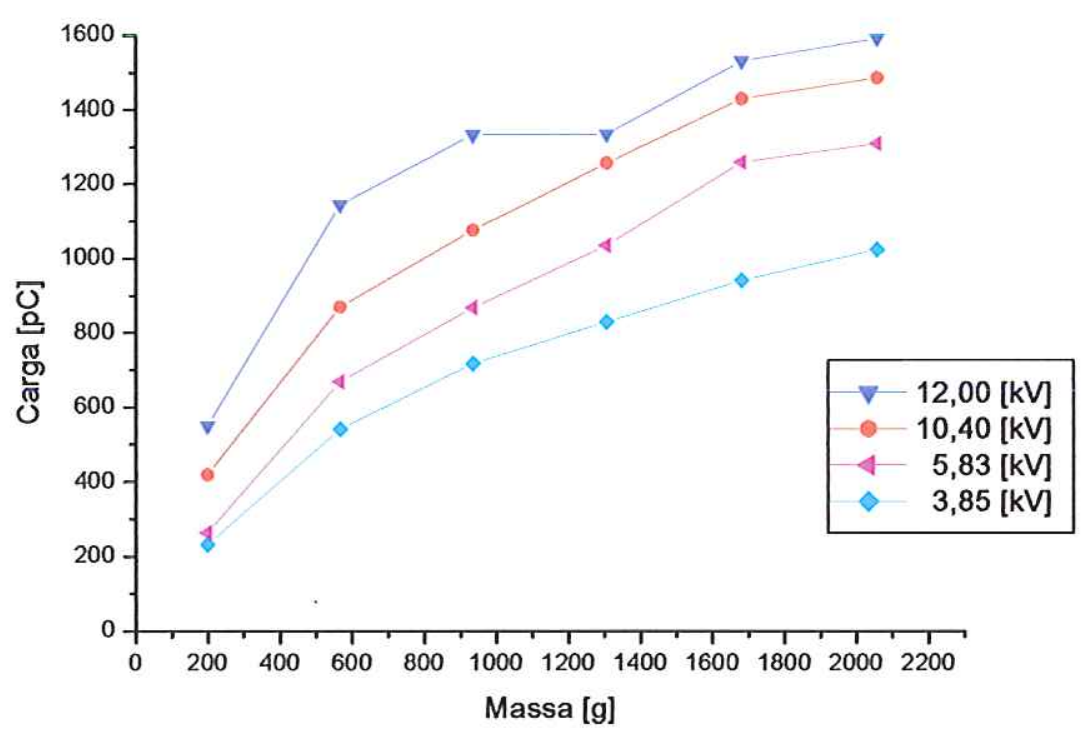

Figura 3.7-Curvas Carga [pC] x Massa aplicada na descompressão [g] para cada tensão de carregamento [kV] 
Observou-se que, para cada valor de tensão de carregamento, as curvas apresentaram características semelhantes, porém aquelas em que a tensão de carregamento da amostra encontrava-se no intervalo compreendido entre $5 \mathrm{kV}$ e $7 \mathrm{kV}$ mostram melhores coeficientes piezoelétricos. As amostras carregadas com tensão menor que $5 \mathrm{kV}$ apresentaram baixos coeficientes piezoelétricos devido ao baixo carregamento a que foram submetidas.

Aquelas que foram carregadas com tensões superiores a $7 \mathrm{kV}$ apresentaram coeficientes piezoelétricos elevados, mas indicavam saturação, ou seja, o aumento do valor da tensão de carregamento não correspondeu ao proporcional acréscimo da constante piezoelétrica.

Uma nova série de amostras foi confeccionada e cada uma delas carregada com tensão de 5,88 kV. Uma a uma, elas foram submetidas à aplicação de pesos de $0,5 \mathrm{~N}$ até $12,5 \mathrm{~N}$ com variação de $0,5 \mathrm{~N}$, e uma série de cinco medições, com o uso do osciloscópio, foi feita a cada descompressão, conforme resultados mostrados na tabela 5 . 
Tabela 5 - Medições das cargas (pC) na amostra selecionada (G7) - descompressão.

\begin{tabular}{|c|c|c|c|c|c|c|c|c|}
\hline Força $[\mathrm{N}]$ & 0,5 & 1,0 & 1,5 & 2,0 & 2,5 & 3,0 & 3,5 & 4,0 \\
\hline \multirow{5}{*}{ 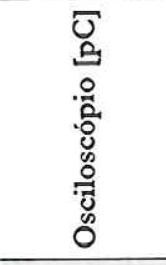 } & 1437 & 2000 & 2094 & 2125 & 2219 & 2594 & 2438 & 2219 \\
\hline & 1563 & 2000 & 2094 & 2062 & 2344 & 2375 & 2375 & 2344 \\
\hline & 1281 & 2000 & 2125 & 2250 & 2406 & 2219 & 2313 & 2250 \\
\hline & 1625 & 2000 & 2125 & 2250 & 2406 & 2375 & 2281 & 2625 \\
\hline & 1469 & 1906 & 2062 & 2156 & 2219 & 2344 & 2344 & 2406 \\
\hline média & 1475 & 1981 & 2100 & 2169 & 2319 & 2381 & 2350 & 2369 \\
\hline
\end{tabular}

\begin{tabular}{|c|c|c|c|c|c|c|c|c|}
\hline Força [N] & 4,5 & 5,0 & 5,5 & 6,0 & 6,5 & 7,0 & 7,5 & 8,0 \\
\hline \multirow{5}{*}{ 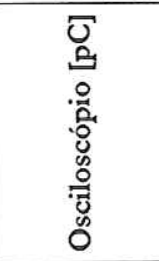 } & 2469 & 2594 & 2687 & 2719 & 2813 & 2713 & 2719 & 2719 \\
\hline & 2469 & 2750 & 2750 & 2844 & 2813 & 2656 & 2719 & 2719 \\
\hline & 2500 & 2656 & 2719 & 2750 & 2844 & 2656 & 2719 & 2719 \\
\hline & 2531 & 2625 & 2656 & 2750 & 2781 & 2781 & 2750 & 2719 \\
\hline & 2375 & 2625 & 2656 & 2750 & 2813 & 2656 & 2719 & 2719 \\
\hline média & 2469 & 2650 & 2694 & 2763 & 2813 & 2692 & 2725 & 2719 \\
\hline
\end{tabular}

\begin{tabular}{|c|c|c|c|c|c|c|c|c|}
\hline Força $[N]$ & 8,5 & 9,0 & 9,5 & 10,0 & 10,5 & 11,0 & 11,5 & 12,0 \\
\hline \multirow{5}{*}{ 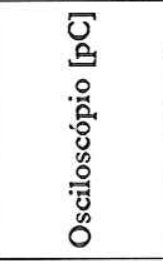 } & 2813 & 2781 & 3062 & 2719 & 2687 & 2938 & 2656 & 2656 \\
\hline & 2781 & 2781 & 2719 & 2750 & 2687 & 2844 & 2656 & 2531 \\
\hline & 2781 & 2844 & 2938 & 2656 & 2500 & 2844 & 2531 & 2938 \\
\hline & 2781 & 2781 & 2938 & 2750 & 2719 & 2969 & 2625 & 2875 \\
\hline & 2781 & 2781 & 2844 & 2687 & 2719 & 2750 & 2687 & 2875 \\
\hline média & 2787 & 2794 & 2900 & 2712 & 2662 & 2869 & 2631 & 2775 \\
\hline
\end{tabular}

Com os valores obtidos foi possível a construção de duas novas curvas: a primeira, figura 3.8, apresenta a carga elétrica medida através do osciloscópio pela força mecânica aplicada (descompressão); a segunda, figura 3.9, representa os valores dos coeficientes de piezoeletricidade $\mathrm{d}_{33}$, calculados conforme a equação (3.2) descrita no item 3.4 pela força mecânica aplicada (descompressão).

Por meio dessas duas curvas, é possível constatar que: para forças de descompressão aplicadas a partir de $6 \mathrm{~N}$, a carga da amostra apresentou valor praticamente constante, em torno de $2800 \mathrm{pC}$ (figura 3.8), e o valor do coeficiente piezoelétrico em torno de $280 \mathrm{pC} / \mathrm{N}$. 


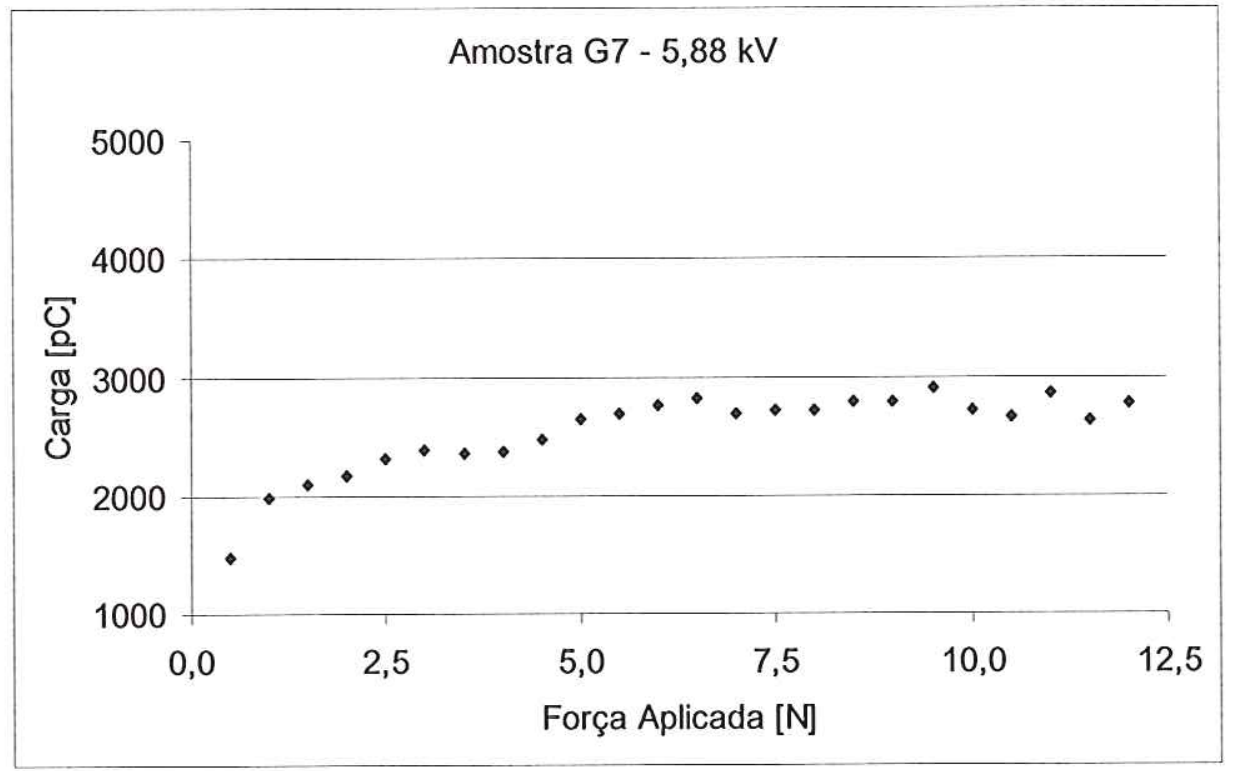

Figura 3.8 - Curva carga [pC] x Força aplicada na descompressão [N] para a amostra G7carregada com $5,88 \mathrm{kV}$

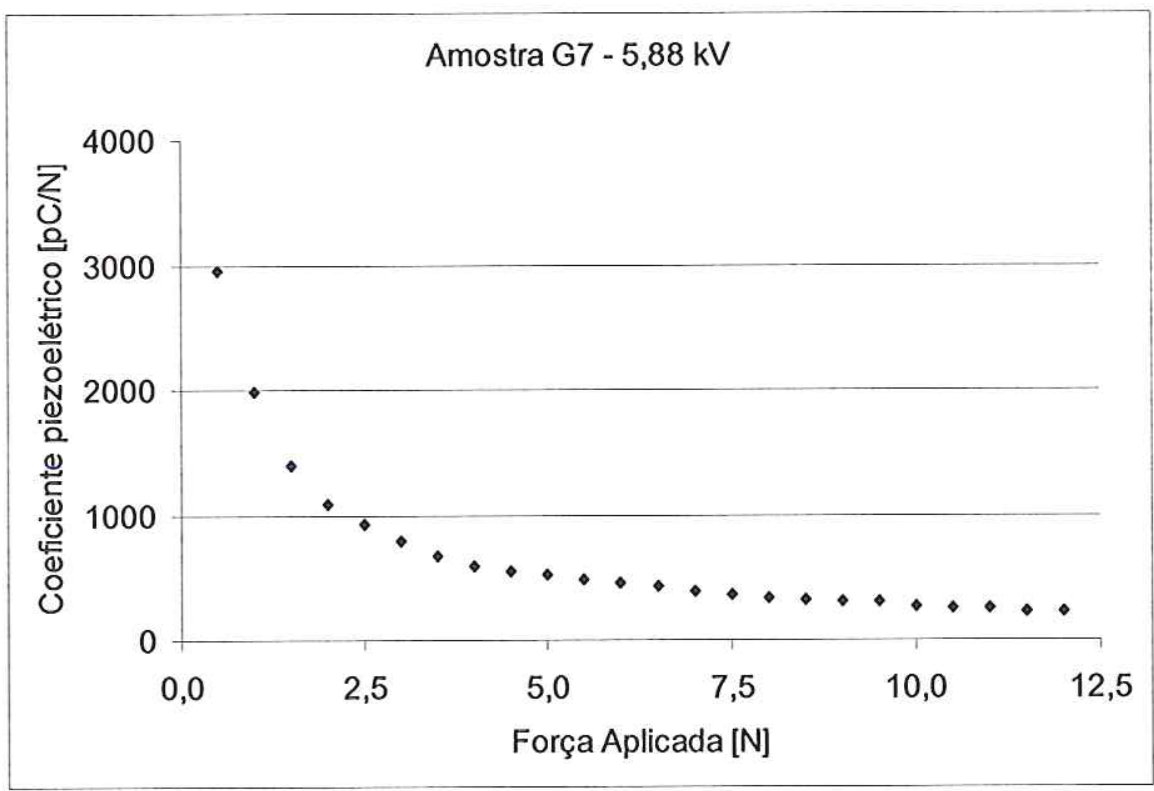

Figura 3.9 - Coeficiente Piezoelétrico [pC/N] x Peso Aplicado na Descompressão [N] para a amostra $\mathrm{G7}$ - Carregada com $5,88 \mathrm{kV}$ 


\subsection{REPETITIVIDADE DO PROCESSO}

Para a comprovação da repetitividade do processo, retomam-se as amostras que foram carregadas com tensão de $5,88 \mathrm{kV}(\mathrm{G} 7)$ e procedeu-se a novas medições. Desta feita, usando o peso de $10 \mathrm{~N}$, foram obtidos os valores mostrados na tabela 6 e representados na figura 3.10 .

Tabela 6 - Cargas elétricas armazenadas nas amostras da série $\mathrm{G}$ com peso de $10 \mathrm{~N}$.

\begin{tabular}{|c|c|c|c|c|c|c|c|c|}
\hline Amostra & 1 & 2 & 3 & 4 & 5 & 6 & 7 & 8 \\
\hline $\begin{array}{c}\text { Carga } \\
\text { Elétrica [pC] }\end{array}$ & 7717 & 6765 & 7904 & 8638 & 7701 & 7691 & 8436 & 6740 \\
\hline
\end{tabular}

\begin{tabular}{|c|c|c|c|c|c|c|c|c|}
\hline Amostra & 9 & 10 & 11 & 12 & 13 & 14 & 15 & 16 \\
\hline $\begin{array}{c}\text { Carga } \\
\text { Elétrica [pC] }\end{array}$ & 7778 & 6734 & 8244 & 9115 & 8342 & 6526 & 8860 & 6500 \\
\hline
\end{tabular}

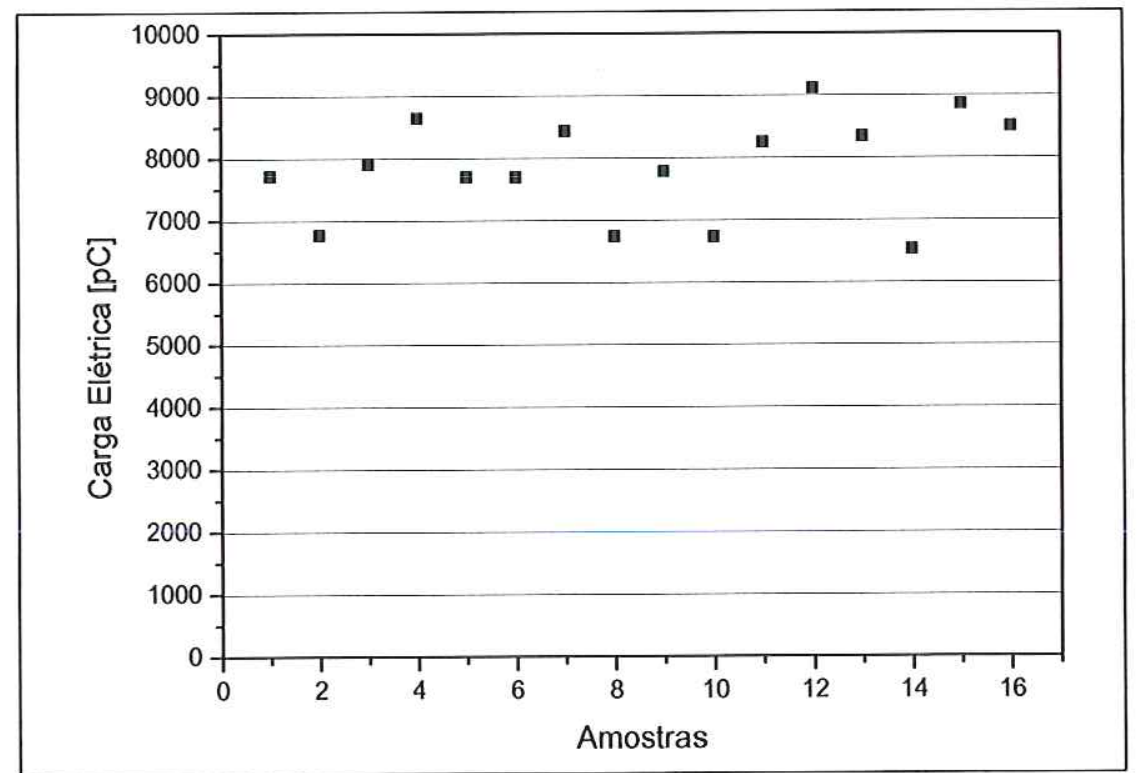

Figura 3.10 - Repetitividade dos valores de carga elétrica encontrados em uma série de amostras carregadas com uma mesma tensãoImpulsiva $-5,88 \mathrm{kV}$ 


\section{CAPÍTULO IV \\ Desenvolvimento Té́rico}

Neste capítulo será proposto um desenvolvimento

teórico para o processo de carregamento e também

para o efeito piezoelétrico observado.

\subsection{CONSIDERAÇÕES GERAIS}

No desenvolvimento do sensor, duas considerações teóricas necessitam ser efetuadas. A primeira relativa ao processo de carregamento das cavidades existentes na interface dos materiais, e a segunda relativa ao princípio físico envolvido no fenômeno da piezoeletricidade.

\subsection{CONSIDERAÇÕES SOBRE O PROCESSO DE CARREGAMENTO}

O processo de carregamento dos interstícios existentes na interface das duas folhas de Teflon FEP assemelha-se àquele já apresentado por Altafim e outros nas referências [9]. Nesta referência, as cavidades preenchidas com ar foram deliberadamente criadas entre o eletrodo superior metálico e o Teflon FEP, como ilustra a figura 4.1. 


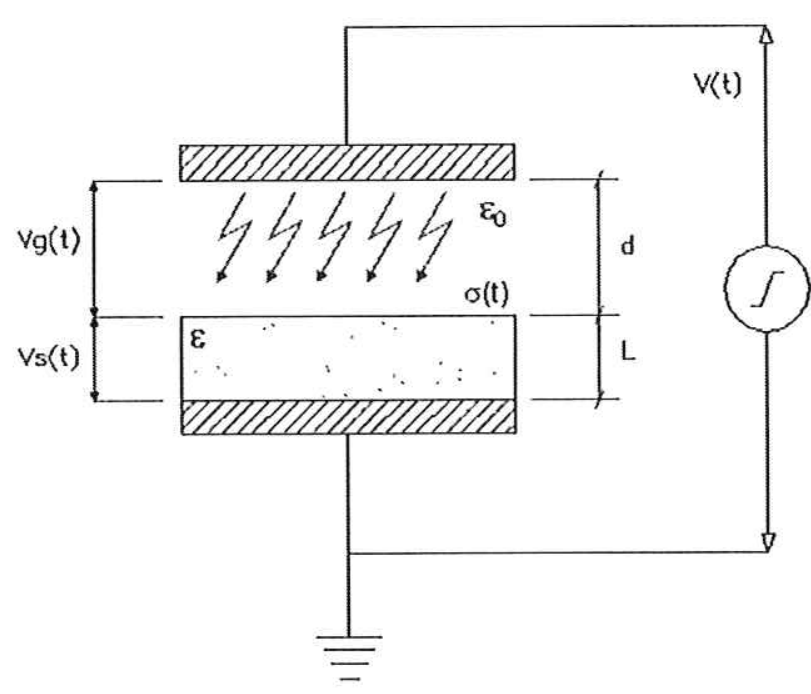

Figura 4.1 - Diagrama esquemático para carregamento de eletretos por tensões impulsivas.

Nesse método, uma tensão impulsiva singela com formato dado pela equação (4.1) é aplicada sobre dois eletrodos separados por um dielétrico, no caso o Teflon FEP. As cargas elétricas transferidas do eletrodo superior para o dielétrico por descargas elétricas armazenam-se em armadilhas energéticas superficiais profundas, criando um eletreto do tipo cargas espaciais. Este método de carregamento apresenta como uma das principais vantagens seu curtíssimo tempo de carregamento, da ordem de microssegundos e sua extrema simplicidade.

$$
v(t)=v_{0}\left(e^{-\alpha_{1} \cdot t}-e^{-\alpha_{2} \cdot t}\right)
$$

onde $\mathrm{v}_{0}$ é a tensão de pico, e $\alpha_{1}$ e $\alpha_{2}$ são constantes de tempo. No caso dos interstícios de ar, localizados na interface das duas folhas de Teflon e entre a folha de alumínio e o Teflon, como ilustrado na figura 4.2, também ocorrem descargas elétricas, quando o conjunto fica submetido a tensões impulsivas. E da mesma forma, cargas elétricas são transferidas e aprisionadas nas paredes isolantes das cavidades. Quando as duas paredes são isolantes, cada uma delas carrega-se com polaridade oposta à outra, formando pequenos dipolos. Quando apenas uma delas é isolante, ela carrega-se com uma carga igual à do eletrodo mais próximo. As paredes passam, desta forma, a funcionar como 
eletrodos recobertos por um dielétrico, e todo o fenômeno pode ser explicado nos parágrafos subseqüentes.

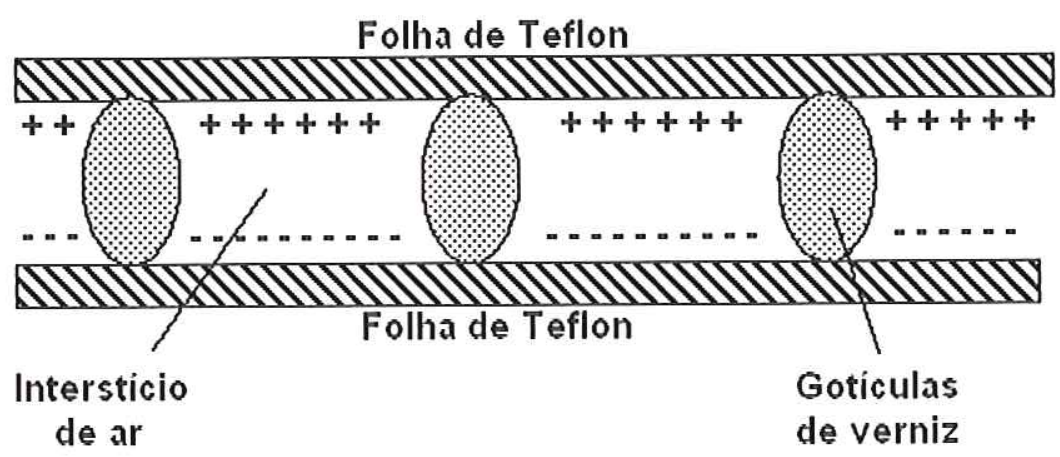

Figura 4.2 - Interstício existente entre as folhas de Teflon FEP quando separadas por gotículas de verniz.

Para melhor entendimento do processo de carregamento do filme dielétrico, é necessário considerar o arranjo mostrado na figura 4.1. O arranjo em questão é composto de um gerador capaz de produzir altas tensões de curta duração, ou seja, impulsivas. Seus terminais são ligados aos eletrodos, o inferior recebendo a amostra de dielétrico através de sua face metalizada. A parte oposta do dielétrico estará voltada para o eletrodo superior e, entre esta face e o eletrodo superior, encontra-se a abertura preenchida de ar, denominada de interstício.

Quando, por exemplo, uma tensão negativa $V(t)$ é aplicada aos eletrodos, surge uma diferença de potencial no interstício, $\mathrm{V}_{\mathrm{g}}(\mathrm{t})$, que cresce até atingir o valor crítico $\mathrm{V}_{\mathrm{c}}(\mathrm{t})$, produzindo, ao atingir valores específicos, uma descarga negativa. As cargas negativas assim produzidas são transferidas para o dielétrico, sendo ali aprisionadas, formando o eletreto.

Para que uma determinada densidade de carga $\sigma$ seja armazenada no dielétrico, a diferença de potencial no interstício será dada por: 


$$
j_{c}=\frac{d \sigma(t)}{d t}
$$

onde, ainda de acordo com a figura $4.1, \mathrm{j}_{\mathrm{c}}(\mathrm{t})$ é a densidade de corrente no interstício.

O campo elétrico no interstício pode ser determinado como:

$$
E_{g}(t)=\frac{v_{g}(t)-v_{s}(t)}{d+\frac{L}{\varepsilon}}
$$

onde: $v_{\mathrm{s}}(\mathrm{t})$ é chamado de potencial de superfície em circuito aberto [21], e definido como:

$$
v_{s}(t)=\frac{\sigma(t) l}{\varepsilon \varepsilon_{0}}
$$

em que $\varepsilon_{0}$ é a permitividade no vácuo, $\varepsilon$ é a permitividade relativa do dielétrico, $\mathrm{d}$ e $\mathrm{L}$ são as espessuras do interstício e da amostra do dielétrico, respectivamente.

De acordo com a teoria da pré-descarga de Townsend [22, 24],

$$
j_{c}(t)=\frac{j_{0} e^{\alpha d}}{1-\left(\gamma e^{\alpha d}-1\right)}
$$

em que, $\alpha$ (coeficiente de ionização) e $\gamma$ são o primeiro e o segundo coeficientes de Townsend, respectivamente.

O coeficiente de ionização $\alpha(t)$, no caso, é dependente do tempo e é representado pela expressão:

$$
\alpha(t)=A p e^{\left[-\frac{B p}{E_{s}(t)}\right]}
$$


No ar, a expressão (4.6) assume valores que variam de 75 a $600 \mathrm{VPa}^{-1} \mathrm{~m}^{-1}$ [24].

A densidade de corrente $\mathrm{j}_{\mathrm{c}}(\mathrm{t})$ da equação (4.5) torna-se importante para $\mathrm{o}$ carregamento somente próximo à disruptura (quando o denominador da equação se aproxima de zero). $\mathrm{O}$ valor $\alpha(\mathrm{t})$ da expressão (4.6) cresce rapidamente quando $\mathrm{E}_{\mathrm{g}}(\mathrm{t})$ assume valores próximos do valor de Bp e o denominador da equação (4.5) se aproxima de zero. Como se pode observar, o carregamento do filme somente apresenta o carregamento $\mathrm{E}_{\mathrm{g}}(\mathrm{t})$ próximo ao valor de ruptura.

A figura 4.3 mostra a disposição do eletreto formado logo após o método das descargas impulsivas de alta tensão.

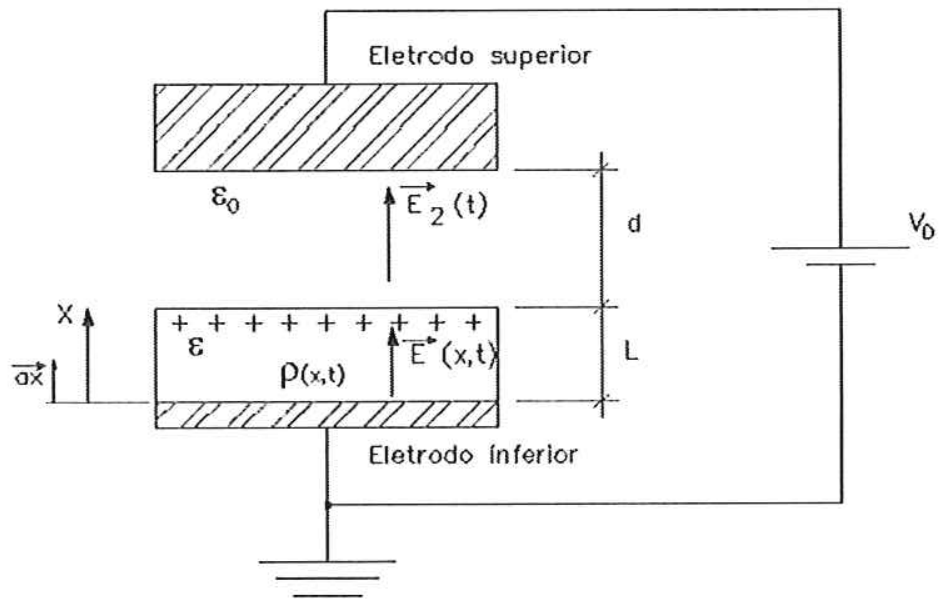

Figura 4.3 - Arranjo para um eletreto formado por tensões impulsivas.

O potencial de superfície no filme, após o carregamento através da descarga, é proporcional à densidade superficial de carga e pode ser facilmente medido pelo processo de circuito aberto [8]. A tensão de impulso é obtida através de um gerador Marx e é dada pela expressão $4.1 \operatorname{com} \alpha_{1}^{-1}=45 \mu \mathrm{s} \mathrm{e} \alpha_{2}^{-1}=1,2 \mu \mathrm{s}$. Como $\alpha_{1}{ }^{-1} \ll \alpha_{2}{ }^{-1}$, a tensão de impulso apresenta o comportamento de uma rampa com tempo de subida $\alpha_{2}$. 
Para $\mathrm{t} \ll \alpha_{2}{ }^{-1}$, a expressão (4.1) fica:

$$
v(t)=v_{0} \alpha_{2} t
$$

Após o máximo valor da tensão de impulso $v_{0}$, ela decresce até zero. Durante esse decaimento, o campo no interstício muda de sinal. O depósito de cargas na superfície do dielétrico produz um campo reverso de valor igual ou superior ao expresso em:

$$
E_{g \min }=\frac{v_{0 \min }}{d+\frac{L}{\varepsilon}}
$$

e ocorre a descarga de retorno que pode resultar na neutralização de parte das cargas depositadas. Esse fenômeno é conhecido como descarga reversa de Paschen, que pode ser o responsável pela saturação no carregamento observado no capítulo anterior.

\subsection{COMPORTAMENTO PIEZOELÉTRICO DO NOVO SENSOR}

Uma vez carregadas as cavidades, tem-se um eletreto em seu interior, ou seja, ali existe um campo elétrico permanente. Qualquer alteração da geometria, no caso redução ou aumento das espessuras das cavidades, irá induzir cargas nos eletrodos externos, de forma semelhante a capacitores carregados quando tem suas placas aproximadas ou afastadas. Cargas assim induzidas geram tensões proporcionais aos deslocamentos quando colocadas em uma configuração como mostrada na figura 4.4. No caso, o efeito piezoelétrico pode ser explicado justamente porque a redução e o aumento das espessuras da cavidade são conseguidos aplicando-se ou retirando-se a pressão sobre os eletrodos. 


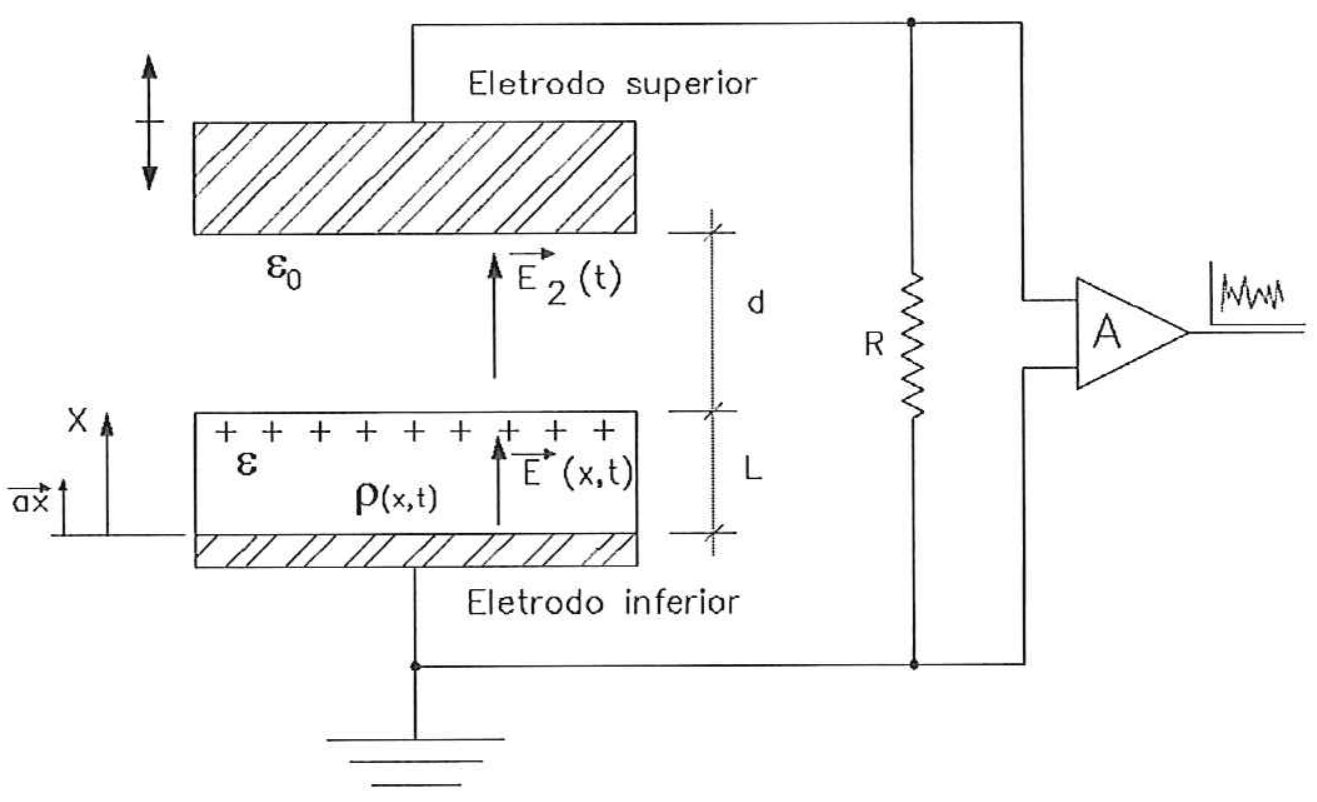

Figura 4.4 - Alteração das espessuras das cavidades de ar alteram o efeito piezoelétrico. 


\section{CAPÍTULO V}

CONCLUSÕES

Neste capítulo será feita a análise conclusiva do trabalho e apresentadas propostas de novos trabalhos.

\subsection{CONCLUSÃO}

Os resultados obtidos com as medições efetuadas nas amostras dos eletretos permitem concluir que o sensor proposto corresponde aos objetivos esperados:

- O sensor apresentou em sua curva de resposta à ação de esforço peso, grande faixa de linearidade, de $0,6 \mathrm{~N}$ até $1,8 \mathrm{~N}$;

- A partir de certo valor de carga aplicada o sensor não mais responde aos valores de piezoeletricidade esperados podendo ficar definitivamente danificados. Isto é explicado, possivelmente pelo rompimento das bolhas de verniz existente entre as lâminas de Teflon FEP, o que causa o deslocamento das cargas elétricas para fora do espaço de ar onde estavam presas;

- Dentro dos limites de carga aplicada há repetitividade do processo;

- Os valores de constate piezoelétrica estática encontrados estão são comparáveis aos maiores valores obtidos com polímeros celulares, em torno de $290 \mathrm{pC} / \mathrm{N}$, o que nos permite obter sensores de boa qualidade com materiais de fácil obtenção no mercado, com custos bastante reduzidos e, independente de tecnologia importada; 
- Os custos para produção de uma amostra podem ser comparados aos de um sensor convencional, ao redor de $\mathrm{R} \$ 45,00$, computando-se os custos dos materiais empregados em sua elaboração:
1 - Teflon FEP
$\mathrm{R} \$ 18,60 / \mathrm{m}^{2}$.
2 - Verniz
$\mathrm{R} \$ 3,00 / 300 \mathrm{ml}$.
3 - Lâmina de Alumínio
$\mathrm{R} \$ 1,06 / \mathrm{m}^{2}$.

Para a produção de uma amostra o custo encontra-se ao redor de $\mathrm{R} \$ 0,10$.

Muito ainda é necessário fazer para um completo entendimento desses novos sensores, por exemplo:

- Verificação da região de linearidade do processo, carregando-o com diferentes pesos;

- Comparar os dois processos de medidas do coeficiente piezoelétrico;

- Melhorar a repetitividade do processo;

- Verificar a sensibilidade da região linear;

- Comparar os processos de medida do coeficiente estático;

- Determinar o comportamento dinâmico da amostra.

Neste contexto, inúmeros estudos futuros poderão ser efetuados, sendo que alguns deles encontram-se citados abaixo:

- Estudos sobre o comportamento dinâmico do sensor; 
- Melhoria do processo de implantação dos eletrodos de alumínio;

- Melhoria do processo de colagem das folhas de Teflon FEP;

- Estudos sobre outros espaçamentos e sua influência no processo de carregamento;

- Confirmação da teoria proposta no capítulo IV através de novos testes;

- Desenvolvimento de novas tecnologias de sensores, baseado na idéia de criar microporos nas interfaces de dois polímeros.

Contudo, o novo sensor abre um amplo leque de possibilidades para o desenvolvimento de novos produtos em diferentes áreas tecnológicas, que têm como cerne sensores de pressão dinâmicos. Dentre essas áreas, podem-se citar: engenharia biomédica, engenharia mecânica; engenharia elétrica.

Desta dissertação foi produzido um trabalho [40] apresentado no 2003 Annual Report Conference on Electrical Insulation and Dielectric Phenomena - CIDEP no mês de outubro, com excelente aceitação. 


\section{REFERÊNCIAS BIBLIOGRÁFICAS}

[1] HILCZER B.; MATECKI, J. (1986). Electrets. Tradução de Juzy Tomascecyk. Amsterdam: Elsevier; New York: PWN-POLISH Scientific. Cap.1, p.1-18.

[2] GROSS, B. (1944). Experiments on electrets. Physical Review, Woodbury, v.66, n.1/2, p.26-28, July.

[3] GROSS, B.; DENARD, L.F. (1945). On Permanent charges in solid dielectrics. I - dielectric absorption and temperature effects in carnauba wax. Physical Review, Woodbury, v.67, n.7/ 8, p.253-259, Apr.

[4] GROSS, B. (1950). Static charges on dielectrics. British Journal Applied Physics, London, v.1, p.259-267, Jun.

[5] EGUCHI, M. (1919). Variation of electrical conductivity of oils and waxes. Proceedings of Physico-Mathematical Society of Japan, Tokio, v.1, p.320-326, Nov.-Dec.

[6] GERHARD-MULTHAUPT, R. (2002). Voided polymers electrets - new materials, new challenges, new chances. In: INTERNATIONAL SYMPOSIUM ON ELECTRETS, 11., 2002, Melbourne. Proceedings... Melbourne: IEEE, p.36-45.

[7] GROSS, B. (1964). Charge storage in solid dielectrics - a bibliographical review on the electret and related effects. Amsterdam: Elsevier.

[8] SESSLER, G.M.; GERHARD-MULTHAUPT, R. (Ed.). (1999). Electrets. $3^{\text {rd }}$.ed. Morgan Hill: Laplacian Press. 
[9] ALTAFIM, R.A.C.; GIACOMETTI, J.A.; JANISZEWSKI, J.M. (1992). A Novel method for electret production using impulse voltages. IEEE Transactions on Electrical Insulation, New York, v.27, n.4, p.739-743, Aug.

[10] - (1992). An electret transducer for impulse voltage measurements. IEEE Transactions on industry applications, v.28, n. 5, p.1217-1222, Sep.-Oct.

[11] SESSLER, G.M. (Ed.). (1987). Electrets - topics in applied physics. $2^{\text {nd }}$. ed. New York: Springer-Verlag. V.33, p.285-319.

[12] PILLAI, P.K.C.; ARYA, S.K. (1972). The Photoelectret state formation and its temperature dependence thin-films of CdS. Solid-State Electronics, London, v.15, n.11, p.1245-1251, Apr.

[13] ANDREICHIN, R. (1975). High-field polarization, photopolarization and photoelectret properties of high-resistance amorphous semiconductors. Journal of Electrostatics, Amsterdam, v.1, n.3, p.217-230, Aug.

[14] KUEFFEL, E.; ZAENGL, W.S. (1984). High-voltage engineering fundamentals. Oxford: Pergamon. Cap.5, p.297-421.

[15] SESSLER, G.M.; WEST, J.E. (1972). Production of high quasipermanent charge densities on polymer foils by application of breakdown fields. Journal Applied Physics, Menasha, v.43, n.3, p.922-926, Mar.

[16] CHUDLEIGH, P.W. (1976). Mechanism of charge transfer to a polymer surface by conducting liquid contact. Journal of Applied Physics, Menasha, v.47, n.10, p.4475-4483, Oct.

[17] CHUDLEIGH, P.W.; COLLINS, R.E.; HANCOCK, G.D. (1973). Stability of liquid charged electrets. Applied Physics Letters, Woodbury, v.23, n.5, p.211212 , Sept.

[18] MEDYCKI, W.; HILCZER, B. (1987). An Efficient method of production of high charge density electrets. Journal of Electrostatics, Amsterdam, v.19, n.2, p.205-207, May. 
[19] SAWA, G.; LEE, D.C.; IEDA, M. (1975). Discharge current from corona charged polyethylene. Japanese Journal Applied Physics, Tokyo, v.14, n.5, p.643-649, May.

[20] MORENO, R.A.; GROSS B. (1976). Measurement of potential building and decay, surface charge density, and charging currents of corona-charged polymer foil electrets. Journal of Applied Physics, Menasha, v.47, n.8, p.3397-3402, Aug.

[21] GIACOMETTI, J.A., LEAL FERREIRA, G.F.; GROSS, B. (1988). A Summary of corona charging methods. In: INTERNATIONAL SYMPOSIUM ON ELECTRETS, 6., 1988, Oxford. Proceedings... Oxford: IEEE. p.87-91, Sept.

[22] GIACOMETTI J.A.; OLIVEIRA JR., O.N. (1992). Corona charging of polymers. IEEE Transactions on Electrical Insulation, New York, v.27, n.5, p.924-943, Oct.

[23] CAMPOS, J.S.C. (1990). Novo triodo corona e sua aplicação no estudo das propriedades elétricas do polímero PVDF. 102p. Tese (Doutorado) - Instituto de Física e Química de São Carlos, Universidade de São Paulo, São Carlos, 1990.

[24] ALTAFIM, R.A.C.; LEAL FERREIRA, G.F.; GIACOMETTI, J.A. (1998). Self-controlled pre-breakdown discharges in planar symmetry. IEEE Transactions on Dielectrics and Electrical Insulation, New York, v.5, n.1, p.7781, Feb.

[25] BRAIN, K.R. (1924). Investigations of piezo-electric effects with dielectrics. Proceedings of Physical Society, London, v.36, n.81, p.81-93, Dez. 1923 - Aug. 1924.

[26] FUKADA, E.; YAMAMURA, I.; TAMURA, M. (1968). Polypepitides piezoelectric transducers. In: INTERNATIONAL CONGRESS OF ACOUSTIC, 6., Tokyo. Proceedings... p.D69-D71. 
[27] GERHARD-MULTHAUPT, R. (2002). Less can be more - holes in polymers lead to a new paradigm of piezoelectric materials for electret transducers. IEEE Transactions on Dielectrics and Electrical Insulation, New York, v.9, n.5, p.850-859, Oct.

[28] HAYAKAWA, R.; WADA, Y. (1971). A General description of piezoelectricity of polymer films. In: OKA, S.(Ed.) Reports on progress in polymer physics in Japan, Japan: Tokyo Institute of Technology. v.14, p.467-470.

[29] (1973). Piezoelectricity and related properties of polymer films. Advances in Polymer Science, Berlin, v.11, p.1-55. . (1976). Piezoelectricity and pyroelectricity of polymer films arising from heterogeneity and embedded charges. In: OKA, S.(Ed.) Reports on progress in polymer physics in Japan, Japan: Tokyo Institute of Technology. v.19, p.312-324.

[31] DREYFUS, G.; LEWINER, J. (1973). Piezoelectricity induced by charge injection in thin polymer films. In: INTERNATIONAL CONFERENCE ON ELECTRETS, CHARGE STORAGE AND TRANSPORT IN DIELECTRICS, 2., 1972, Miami. Proceedings... Princeton: The Electrochemical Society. p. 517-528.

[32] SESSLER, G.M.; HILLENBRAND, J. (1999). Electromechanical response of cellular electret films. In: INTERNATIONAL SYMPOSIUM ON ELECTRET, 10., 1999, Delphi. Proceedings... Piscataway: IEEE. p.261-264, Sep.

[33] FUKADA, E. (2000). Special issue papers - history and recent progress in piezoelectric polymers. IEEE Transactions on Ultrasonics, Ferroelectrics and Frequency Control, New York, v.47, n.6, p.1277-1290, Nov.

[34] GERHARD-MULTHAUPT, R. et al. (2002). Electrode poling of cellular polypropylene films with short high-voltage pulses. In: IEEE CONFERENCE ELECTRICAL INSULATION AND DIELECTRIC PHENOMENA, 2002, 
Cancum. Annual Report... Piscataway: IEEE Dielectrics and Insulation Society. p.299-302, Oct. . (1999). Preliminary study of multi-layer space-charge electrets with piezoelectric properties from porous and non-porous teflon films. In: INTERNATIONAL SYMPOSIUM ON ELECTRET, 10., 1999, Delphi. Proceedings... Piscataway: IEEE. p.273-276, Sep.

[36] VON ENGEL, A. (1965). Ionized gases. $2^{\text {nd }}$.ed. Oxford: Clarendon Press. Cap.7, p.171-216.

[37] HILLENBRAND, J.; SESSLER, G.M. (2000). Piezoelectricity in cellular electret films. IEEE Transactions on Dielectrics and Electrical Insulation, New York, v.7, n.4, p.537-542, Aug.

[38] WEINHOLD, T. et al. (2000). Porous polytetrafluoroethylene (PTFE) singlefilm space-charge electrets with high piezoelectric coefficients. In: INTERNATIONAL CONFERENCE ON MEASUREMENTS AND APPLICATIONS, 8., 2000. Proceedings... Piscataway: IEEE. p.380-385, Sept.

[39] FARIA, R.M. (1996). A Direct current piezoelectric effect in fluorinated ethylene-propylene copolymer due to space charge. Applied Physics Letters, Woodbury, v.69, n.13, p.1972-1974, Sept.

[40] ALTAFIM, R.A.C. et al. (2003). Piezoeletricity of multi-layers space-charging eletrets from teflon FEP film with homogeneous voids distributed on its surface. In: IEEE CONFERENCE ON ELECTRICAL INSULATION ON DIELECTRIC PHENOMENA, 2003, Albuquerque. Annual Report... Piscataway: IEEE. p.225-228, Sept.-Oct. 